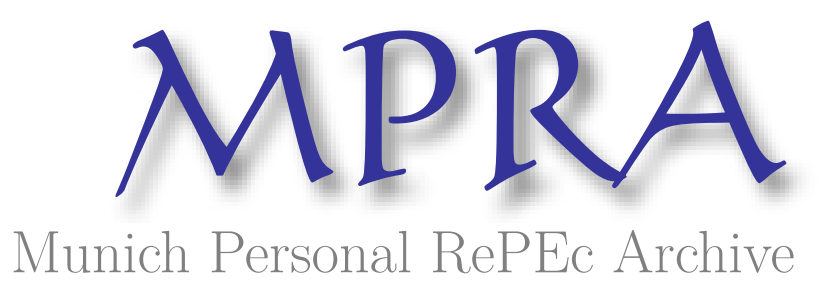

\title{
Representative time use data and new harmonised calibration of the American Heritage Time Use Data (AHTUD) 1965-1999
}

Merz, Joachim and Stolze, Henning

November 2008

Online at https://mpra.ub.uni-muenchen.de/11651/

MPRA Paper No. 11651, posted 19 Nov 2008 10:12 UTC 


\section{electronic International Journal of Time Use Research}

volume 5

number 1

november 2008

ISSN 1860-9937

\section{contents}

Viktor Artemov and Olga Novokhatskaya: Changes in the use of time and the state of health of the Russian population in the 1980s-1990s

Rainer Hufnagel: Entropy and stability in time use - An empirical investigation based on the German Time Use Survey

Hannu Pääkkönen: Alone at home

David Deal: Time for play - An exploratory analysis of the changing consumption contexts of digital games

Joachim Merz and Henning Stolze: Representative time use data and new harmonised calibration of the American Heritage Time Use Data (AHTUD) 1965-1999

Time-pieces

- New developments in time-technology projects, data, computing, services

- Book notes by Kimberly Fisher 


\title{
Representative time use data and new harmonised calibration of the American Heritage Time Use Data (AHTUD) 1965-1999
}

\author{
Joachim Merz and Henning Stolze
}

\author{
Univ.-Prof. Dr. Joachim Merz, Dipl.-Kfm. Henning Stolze \\ Leuphana University of Lüneburg \\ Research Institute on Professions (Forschungsinstitut Freie Berufe, FFB) \\ Campus Scharnhorststr. 1 \\ 21335 Lüneburg, Germany \\ e-mail: merz@uni-lueneburg.de
}

\begin{abstract}
Representative and reliable individual time use data, in connection with a proper set of socio-economic background variables, are essential elements for the empirical foundation and evaluation of existing and new theories in general and in particular for time use analyses. Within the international project Assessing Time Use Survey Datasets several potentially useful individual US time use heritage datasets have been identified for use in developing an historical series of non-market accounts. In order to evaluate the series of American Heritage Time Use Data (AHTUD) $(1965,1975,1985,1992-94,1998-99)$ this paper analyses the representativeness of this data when using given weights and provides a new harmonised calibration of the AHTUD for sound time use analyses. Our calibration procedure with its ADJUST program package is theoretically founded on information theory, consistent with a simultaneous weighting including hierarchical data, ensures desired positive weights, and is well-suited and available for any time use data calibration of interest. We present the calibration approach and provide new harmonised weights for all AHTUD surveys based on a substantially driven calibration framework. To illustrate the various application possibilities of a calibration, we finally disentangle demographic vs. time use behavioural changes and developments by re-calibrating all five AHTUD surveys using 1965 population totals as a benchmark.
\end{abstract}

JEL-Codes: J22, J29, J11, Z0

Keywords: $\quad$ Representative time use data, calibration (adjustment re-weighting) of microdata, information theory, minimum information loss principle, American Heritage Time Use Data (AHTUD), ADJUST program package

This paper is a part of the international project Assessing Time Use Survey Datasets supported by Yale University with Prof. Dr. Andrew S. Harvey (Project Head), Time Use Research Program (TURP), at St. Mary's University, Halifax, NS, Canada; Prof. Dr. Ignace Glorieux, Tempus Omnia Revelat (TOR), Faculty of Economic, Social and Political Sciences, Vrije Universiteit Brussel, Brussels, Belgium; Prof. Dr. Joachim Merz, Research Network on Time Use (RNTU), Research Institute on Professions (FFB), Department of Economics, Behavioural and Law Sciences, Leuphana University of Lüneburg, Lüneburg, Germany; and Klas Rydenstam, Statistics Sweden. This project is supported by Yale University and the Glaser Progress Foundation.

Many thanks to Diane Herz (Bureau of Labour Statistics, USA), and her colleagues for providing the CPS information and all their support. Besides our project partners we also wish to thank the participants of the IATUR 2005 Conference in Halifax for their helpful comments on an earlier version and Jonathan Gershuny and Kimberly Fisher from the Oxford Centre for Time Use Research for clarifying differences between our AHTUD and their further developments with the American Heritage Time Use Study (AHTUS). 


\section{Introduction}

Representative and reliable individual time use data, in connection with a proper set of socioeconomic background variables, are not only essential elements for the empirical foundation and evaluation of existing theories - in general and in particular for time use analyses - but also for the search for new empirical based hypotheses about individual behaviour in the household/ family context. Within the international project Assessing Time Use Survey Datasets several potentially useful individual US time use heritage datasets have been identified for use in developing a historical series of non-market accounts. In order to evaluate the series of American Heritage Time Use Surveys (1965, 1975, 1985, 1992-94, 1998-99) this paper analyses the representativeness of this original data when using given weights and provides a new harmonised calibration of all five AHTUD files for sound time use analyses.

When using the given individual weights it will become evident that there will be a serious bias in all of these files concerning demographic population representation for characteristics which are of strategic importance for substantive time use research analyses. However, when using proper weights the enormously content rich diary data will be demographically representative. Our study provides such proper individual weights with a new harmonised AHTUD calibration which circumvents the biases by delivering adequate and comprehensive demographic calibration weights for all five incorporated US time use surveys as they were available for our project (further abbreviated as American Heritage Tine Use Data, AHTUD).

Our calibration procedure is theoretically founded on information theory (minimum information loss principle with its ADJUST program package), is consistent with a simultaneous weighting including hierarchical data (like personal and family/household data), ensures desired positive weights, and is well-suited and available for any time use data calibration of interest.

We present the calibration approach and provide new harmonised weights for all AHTUD surveys based on a substantially driven calibration framework for sound time use analyses. To illustrate the various application possibilities of a calibration, we finally disentangle demographic vs. time use behavioural changes and developments by re-calibrating all five AHTUD surveys using 1965 population totals as a benchmark.

This paper is divided as follows: We start with a brief description of the methodological background of our calibration procedure based on information theory, including a survey of alternative calibration procedures used by other surveys and microsimulation models (chapter 2). Particularities of time use diary adjustments are discussed in chapter 3 and a solution is shown - exemplified with the actual German Time Use Survey. In chapter 4, a substantively driven calibration framework for time use analyses is developed, sketching microeconomic labour supply of women within the household context, household production/ time allocation, multiple market and non-market analyses, as well as policy impacts of tax and transfer sys- 
tems in the formal and informal economy. Chapter 5 provides the result of our new harmonised calibration of the five heritage files 1965, 1975, 1992-94, and 1998-99 and shows the former bias for important demographic characteristics when using the survey's given calibration weights which are erased by our new weightings. As an example for the various calibration possibilities we disentangle demographic vs. behavioural changes by re-calibrating in chapter 6 using the demographic totals from the earliest survey 1965 as the new demographic totals for all four younger files. We conclude with some recommendations for further time use analyses.

This study was undertaken as a part of an initial component of a larger project, launched in 2003, designed to identify historical American Time Use data and explore its potential for facilitating historical analysis in conjunction with the American Time Use Study launched the same year. The larger project was undertaken through the Time Use Research Program of Saint Mary's University for the "Yale Program on Nonmarket Accounts: A Project on Assessing Time Use Survey Datasets." Five historical datasets readily available when the project was launched, assembled as the American Historical Time Use Data Set (AHTUD) data set, provided the input to the analysis presented here. Subsequent work incorporating additional and improved data is now available as the American Heritage Time Use Study (AHTUS) data set developed by the Oxford Centre for Time Use Research ${ }^{1}$. They provide further edited respective data files, detailed documentation and further support when using the data files from their archive (www.timeuse.org/ahtus).

\section{The adjustment/ calibration of microdata - the- ory, methods and ADJUST software}

A calibration/ re-weighting of the AHTUD was necessary in particular for several reasons:

- First of all, we observed that the available AHTUD respective survey weights do not fit desired totals and thus show a substantial bias.

In addition, there are further requirements to be fulfilled for any sound time use analysis:

- Second, as far as we know, not all of the given weights of the different AHTUD files use an interdependent calibration between different weighting characteristics. Thus, a consistent calibration, which simultaneously fulfils hierarchical information (e.g. household/ family and personal information), is not assured. It is necessary to remedy this.

- Third, due to the lack of documentation, it was not possible to get sufficient information about the respective calibration procedure and their relevant totals. In particular, it is not

\footnotetext{
1 American Heritage Time Use Study, release 1 (May 2006). Created at the Centre for Time Use Research, United Kingdom, by Kimberly Fisher, Muriel Egerton and Jonathan Gershuny, with Nuno Torres and Andreas Pollmann, and contributions from Anne H. Gauthier and John Robinson. Created for Yale University with initial funding from the Glaser Progress Foundation and supplementary funding from the ESRC
} 
obvious if the demographic information used consider substantial requirements, which are important for any sound time use research analysis. However, a theoretically founded and transparent adjustment procedure is needed and will be provided by our approach.

- Fourth, a comparable and harmonised demographic calibration scheme for all single heritage files is not available. However, such a scheme is desirable for identifying substantial time use behavioural changes over time, independent of further demographic developments.

Our new calibration will consider and fulfill the above requirements for the five AHTUD surveys. We will start with the calibration procedure itself, applying the content driven approach in the second step.

\section{Adjustment need}

To adjust/ calibrate microdata in general is to fit a sample (a survey) to prescribed and known aggregate totals (with synonyms such as control data, restrictions, margins, population totals). For each microunit of a (sample) microdata file a suitable weight is sought so that the weighted sum of all microunit characteristics will then sum up to their externally given aggregates. If a sample is totally random, representative data is easily achieved by multiplying each observation by its reciprocal value of the sampling proportion (e.g. by 100 for a $1 \%$ sample). However, due to quoted sampling, item and unit non-responses, collection and coding problems, merging problems, missing observations etc., almost all actual survey samples are ultimately not at random and need a proper re-weighting.

\section{Adjustment components}

There are three building blocks of an adjustment: the restrictions (totals) to be achieved ( $\mathbf{r}$ ), the sample information matrix ( $\mathbf{S}$ ), and the calibration theory and procedure itself.

The known population characteristics, derived e.g. from a census, provide the microdata frame as a vector $\mathbf{r}$ of the number of $\mathrm{m}$ desired total values. Appropriate aggregate statistics might deliver the single restrictions, which could be given as a multidimensional cross table. In general, the restrictions may originate from aggregate statistics, from other samples, or other models. In our application, the US Current Population Survey (CPS), an ongoing monthly household survey to provide demographic and labour force information, provides the totals to be achieved. Since the CPS is adjusted to the Census, the calibration will fit the Census data, too.

The sample matrix $S$ consists of all microunits (number of n observations) of the sample such as persons, families, households, or firms which are described by the $\mathrm{m}$ various weighting characteristics of the survey participants. If, for example, these microunits are persons, they would be described by age, gender, employment and household/ family characteristics by household size, number of children etc.

The calibration procedure itself should incorporate available sampling information. To incorporate this sampling wisdom, the new weighting factors should be as near as possible to those prescribed weights. Formally speaking, an objective function should minimize the dis- 
tance between the prescribed $\mathrm{n}$ weights $\mathbf{q}$ and the chosen new $\mathrm{n}$ weights $\mathbf{p}$ subject to achieving the desired totals $\mathbf{r}$.

\section{Adjustment formal problem}

Taking all three components together: the calibration problem is to find an n-vector $\mathbf{p}$ of calibration factors minimizing an objective function $\mathrm{Z}(\mathbf{p}, \mathbf{q})$ - a function evaluating the distance between the new adjustment factors $\mathbf{p}$ to be computed and the available factors $\mathbf{q}-$ satisfying the $m$ restrictions $\mathbf{r}$ when summing up the weighted characteristics.

$$
Z(\mathbf{p}, \mathbf{q})=\min ! \quad \text { s.t. } \mathbf{S p}=\mathbf{r}
$$

This adjustment problem is a simultaneous one where, for even a large number of characteristics $(m)$, only a single weighting factor has to be computed for each microunit $j(j=1, \ldots, n)$ which after summing up, fulfills consistently all m hierarchical microdata totals (e.g. household, family and personal information) simultaneously.

The objective function minimizes the distance between new adjustment factors $\mathbf{p}$ and the given factors $\mathbf{q}$ in order to capture already available information and former corrections due to quoted sampling etc. ${ }^{2}$ After calibration, a single absolute adjustment factor/weight for a sample microunit $\mathrm{j}$ represents pj total population microunits.

\section{Alternative adjustment procedures}

There are various procedures and functional forms in quantitative economics where an objective function $\mathrm{Z}(\mathbf{p}, \mathbf{q})$ weights the distance of two (adjustment) factors. In general, procedures with quadratic (unweighted or weighted) and other objective functions (linear or nonlinear) are conceivable. Within the microsimulation context re-weighting is an essential tool: it is used as static aging to achieve an updated actual or future demographic structure (see e.g. Merz 1986).

A solution based on a quadratic and unweighted objective function is used within the German Sfb 3 microsimulation model by the former German SPES project and its successor, the Sonderforschungsbereich 3 (Sfb 3) 'Microanalytic Foundations of Social Policy' at the Universities of Frankfurt and Mannheim Germany (Galler, 1977; Galler and Wagner, 1986). Another example of an early US microsimulation model and its calibration is Hollenbeck 1976 who proposed a quadratic weighted objective function ${ }^{3}$ for the adjustment of the microsimulation models of Mathematica Policy Research, Inc. (MPR) and The Policy Research Group, Inc.

2 If such corrections are not given in advance (or as a simple microunit independent sampling ratio), $\mathrm{q}_{\mathrm{j}}$ would be equal for each microunit $\mathrm{j}(\mathrm{j}=1, \ldots, \mathrm{n})$.

3 Different algorithms may solve a quadratic objective function within a quadraric programming approach, e.g. by Frank and Wolfe (1956), Hildreth (1957) or Houthakker (1960). These procedures often used in operations research, however, become relatively inconvenient for large adjustment problems, particularly for those with many microunits and many characteristics. A constrained quadratic loss function is also used for instance by Stone (1976) and extended by Byron (1978) in an input/output context to estimate large social account matrices. 
A multivariate raking ratio estimator is used by Oh and Scheuren 1980 in their 1973 exact match study to fit several types of sample units (design, analysis and estimation units) (see their bibliography on raking) and in the Simulated Tax and Transfer System (STATS) US microsimulation model (Bridges and Johnston, 1976). The raking ratio estimation, reaching back to Deming and Stephan 1940, uses proportional factors in each iteration to fit the marginals of a multi-way table (see also 'iterative proportional fitting' in Bishop and Fienberg, 1975; and the log linear approach within contingency tables in Mosteller, 1968). The proportional iterative fitting approach shows similar results to our entropy approach. For a further handling of different approaches, like algorithms connected with input/output tables and procedures, see Wauschkuhn (1982) and Merz (1986, Chapt. 7). For further calibration estimation approaches in survey sampling see Deville and Särndal (1992). Särndal and Lundström (2005) and Estevao and Särndal (2006) more recently discussed the estimation in surveys with nonresponse respectively with complex auxiliary information. In contrast to these approaches, Merz (1983b) proposed a Kalman filtering procedure and optimal control theory for the adjustment/calibration task.

Different calibration software packages were recently developed by several statistical offices. CALMAR developed by INSEE (Le Guennec and Sautory, 2003) is a program macro within SAS following a proportional fitting approach, which e.g. is used within the NATSEM microsimulation models in Canberra (Australia). G-Calib 2 has been developed in the SPSS language by Statistics Belgium (Vanderhoeft, 2002). Bascula 4.0 is a development in the Delphi language by Statistics Netherlands (Nieuwenbroek and Boonstra, 2002) and can be used with Blaise. All the forgoing need a host program package and are not available standalone like our calibration package ADJUST discussed below.

Only in the ideal case of a real random sample can the well known Horvitz-Thompson estimator be easily applied as the inverse of the sampling ratio for all microunits.

Our adjustment solution: the adjustment of microdata by the Minimum Information Loss (MIL) principle

As seen above, there are many approaches to weight a sample. However, those procedures may produce negative or zero adjustment factors as within the quadratic approach. In addition, most of them are based on an arbitrarily chosen objective function to be minimized. Since non positive weights will further exclude microunits, only a procedure such as the following which provides only positive weights is appropriate. Another already mentioned prerequisite is to simultaneously take care of adequate weights according to personal and family/household characteristics in a hierarchical setting. Separate personal and household weights, as often used in survey weighting, does not ensure the simultaneous fit to the aggregate personal or household data.

In recent decades, information theory - well known in engineering sciences - has found some applications in economics. Theil's 1967 'information inaccuracy' is used, for instance, to judge the forecasting accuracy of econometric models (Merz, 1980). Measuring income inequality by an approach based on information theory is another example (Theil, 1972). More 
recently, the minimum information approach was used to estimate microeconomic allocation models (Theil, Finke and Flood, 1984; Finke and Theil, 1984).

Within information theory an extension of the entropy concept is the information loss (or gain) when a multinomial distribution $\mathbf{q}=\left(\mathrm{q}_{1}, \ldots, \mathrm{q}_{\mathrm{n}}\right)^{\prime}$ is substituted by a similar distribution $\mathbf{p}$ $=\left(\mathrm{p}_{1}, \ldots, \mathrm{p}_{\mathrm{n}}\right)^{\prime}$

$$
I(\mathbf{p}: \mathbf{q})=\sum_{j} p_{j} \log \left(1 / q_{j}\right)-\sum_{j} p_{j} \log \left(1 / p_{j}\right)=\sum_{j} p_{j} \log \left(p_{j} / q_{j}\right),
$$

with $\quad\left(p_{j}, q_{j}>0\right), \sum_{j} p_{j}=\sum_{j} p_{j}=1 \quad(j=1, \ldots, n)$.

Within this concept, the information loss is evaluated as the expected information before, weighted by $\mathrm{q}_{\mathrm{j}}$, minus the expected information after substitution. For an axiomatic derivation of the connected maximum entropy principle or principle of minimum cross-entropy, see Shore and Johnson (1980), and Jaynes (1957) who first proposed entropy maximisation within engineering purposes.

With reference to the above information theory concept, the adjustment problem under the Minimum Information Loss (MIL) principle then is to minimize the objective function

$$
Z(\mathbf{p}, \mathbf{q})=\min _{\mathbf{p}}\left\{\sum_{j} p_{j} \log \left(p_{j} / q_{j}\right)\right\}
$$

$$
\text { s.t. } \mathbf{S p}=\mathbf{r} \text {. }
$$

where $p_{j}=$ new adjustment factor for a microunit (e.g. household) $j(j=1, \ldots, n) ; q_{j}=$ known adjustment factor for each microunit $\mathrm{j}, \mathrm{n}=$ number of microunits, with $\mathbf{S}_{(\mathrm{m}, \mathrm{n})}=\left[\mathrm{s}_{\mathrm{ij}}\right]$ sample information matrix $(i=1, \ldots, m ; j=1, \ldots, n), \mathbf{r}_{(m)}=\left[r_{i}\right]$ vector of restrictions, $m=$ number of restrictions. The MIL-objective function minimization subject to the simultaneous set of possible hierarchical restrictions fulfills the two main requirements of positive weights and simultaneous consideration of hierarchical data.

This adjustment problem yields a highly non-linear equation system out of the restricted Lagrangean approach. After solving for the $\mathrm{m}$ Lagrange multipliers $\lambda_{\mathrm{k}}(\mathrm{k}=1, \ldots, \mathrm{m})$ iteratively the new adjustment factors with the solution $\lambda$ are given by

$$
p_{j}=\exp \left(\lambda \mathbf{s}^{j}-1\right)
$$

Once the non-linear equation system is solved, the new adjustment factors can be calculated relatively simply: the single given adjustment factor $\mathrm{q}_{\mathrm{j}}$ is multiplied by a term which is determined by a linear combination of the respective microunit (e.g. household and personal) 
weighting characteristics $\left(\mathbf{s}^{j}\right)$ and the Lagrange multipliers. ${ }^{4}$ For a further in-depth discussion see Merz (1983a, 1985, 1994) and Merz and Stolze (2007).

Multiple usages of re-weighting a sample

The calibration of microdata can be used not only to adjust a specific sample to its totals given from another database. There are more and multiple usages of a re-weighting procedure such as for

- Achieving representative results for a given sample and its population

- Descriptive microanalyses

- Micreoeconometrics: weighted estimation

- Sensitivity analyses with alternative artificial totals and respective weightings

- Extrapolating/forecasting samples for an actual demographic situation

- Microsimulation context: static ageing (forecasting by re-weighting), weighting of simulation files

ADJUST software package

Our stand-alone program package ADJUST based on the MIL-principle fulfills the above requirements in an efficient manner for unlimited sample sizes using specific iteration dependent step lengths within a modified Newton-Raphson procedure (Merz and Stolze, 2007). ADJUST has been proven to be successful in many applications: e.g. for the adjustment of the recent German Time Budget Surveys, the Income and Consumption Survey and other surveys of the German Statistical Office or for a refined adjustment of the German SocioEconomic Panel; within the framework of a microsimulation analysis of financial and distributional impacts of the German Pension Reform; for a consistent adjustment for the microsimulation analysis of time allocation impacts in the formal and informal economy of the recent German tax reform. In addition, ADJUST has been successfully used in many academic, government and private enterprises and consulting firm applications. ADJUST is available via http://ffb.uni-lueneburg.de/adjust.

\section{Choosing a content driven calibration frame- work for time use analyses}

To increase the representativeness of a sample with respect to a content driven time use analysis a calibration should incorporate basic demographic variables which are connected with the time use question of interest. Certainly, it is not the final resulting variable which is

4 Usually the above adjustment factors are not formulated as probabilities respectively relative frequencies but rather in absolute terms. The absolute adjustment problem yields the same solution as in the relative case and is only different according to the interpretation with $p_{j}=p_{j} N, q_{j}=q N$ and $r_{i}=r_{i} N(N=$ number of all microunits in the total population). 
calibrated, but its proper socio-demographic background. One example: To investigate time use patterns within the context of different household types (like household with and without children, single parents etc.), the demographic distribution of those household types should be representative (and be calibrated) for further specific household time use analyses of interest.

\section{Dimensions of a content driven calibration framework}

The aim is to find a calibration framework which allows valid demographic data to analyse time use behaviour based on different theoretical socioeconomic approaches. To find such a calibration kernel, we briefly discuss the importance, necessity and application of time use information in explaining behaviour for theoretically based empirical economic and social research, as well as for a targeted economic and social policy.

As a basis, we sketch the economic framework of activity linked time dimensions: the optimal allocation of goods and time with constrained goods and time resources. Within this framework, the microeconomic allocation model, the optimal labour supply, and the household production approach for a model of multiple market and non-market activities is of central importance. Individual time use data, in connection with a proper set of background variables, are essential for an empirical foundation and an evaluation of those theories ('new home economics'), as well as in the search for new empirical based hypotheses about individual behaviour in the household context.

Genuine applications of time budget data with appropriate background variables include:

- Labour supply of women within the household context - microeconomic analyses

- Household production/time allocation

- Multiple market and non-market time use activities - socioeconomic analyses

- Policy impacts of the tax and transfer system - time allocation effects in the formal and informal economy by microsimulation modeling.

These examples and central time use research areas will illustrate the need for and the spread of appropriate background variables and demographic calibration requirements.

\subsection{Labour supply of women within the household context - the microeco- nomic approach}

Within the well known microeconomic allocation model, an individual/household is maximising his/her/its utility based on the amounts of goods. Facing a restricted income, utility maximisation under the money constraint yields an optimal allocation of goods in a static or an intertemporal approach. Based on this microeconomic allocation model, the individual's paid working hours (labour supply) are incorporated into the preference optimization model via leisure (full time minus leisure determines the working hours). Thus, total time is divided into consumption time (leisure) and time for paid work to earn income. Then, maximising utility as a function of the market goods amounts and the consumption time subject to full 
income (all expenditures plus wage weighted consumption time equals non-labour income and wage weighted total time) yields the optimal allocation equations for the goods amounts as well for the working hours (labour supply).

Already within this classical approach socio-economic background variables are necessary to determine

- individual utility function dependent of the socioeconomic status

- individual wage, including the potential wage of nonworkers, which has been econometrically estimated by human capital and other socioeconomic variables

- non-labour income dependent of the socioeconomic status

- hours of paid work.

Within the last decade, empirically based labour supply research using advanced econometric methods has proven the importance not only of time use itself in paid work, but also the need for proper socioeconomic background variables with regard to the mentioned four microeconomic dimensions.

One very important research area is the increased labour market engagement of women, where the household context in particular (children, need for care, family dependent labour force participation) is important. In all the applications, either the household itself is seen as the economic agent or its members are the agents who might bargain about the consumption and time allocation decision [useful early literature includes the survey concerning labour supply by Killingsworth, 1983; concerning female labour supply by Killingsworth and Heckmann, 1986, Chiappori 1988; more recently Chiappori, Blundell, Magnac and Meghir 2007 as well as recent issues in scientific journals (e.g. Journal of Labour Economics)].

In brief: personal (adults and children) as well household demographics have to be representative for further analyses following this strand of time use research.

\subsection{Household production/time allocation}

With the 'new home economics' since the Nobel prize winner Becker (1965), and Lancaster (1966), Muth (1966), and Ironmonger (1972), the above mentioned microeconomic approach has been broadened by household production and the connected time allocation. The utility function is now based on the basic commodities which are produced by the household with its input of non-market time and market goods. Such commodities can be defined broadly (e.g. childcare, homework, and do-it-yourself work). Shadow prices can be assigned for the basic commodities via the dual approach, which have no market price per se. Dependent of the household technology, the shadow prices are dependent or independent of the household production output amount (Merz, 1989).

Within this approach, the optimal allocation problem is solved in three steps:

- Modeling the efficient household technology (duality between production and cost function) 
- Modeling and calculation of the shadow price (price of the basic commodities, duality of cost function, and valued production)

- Utility maximised allocation with regard to output (with shadow prices) or with regard to input (with explicit functionalised market goods and the necessary time for the production).

In all three steps, an empirical sound model needs the appropriate personal and household sociodemographic background variables in addition to its specific further information.

\subsection{Multiple market and non-market time use activities - socio-economic analyses}

To explain and estimate a proper household production function with different commodities, different time inputs and their dependencies on the socioeconomic background are necessary. If this approach is expanded by multiple paid market activities (multiple labour supply) possibly including tax and transfers - then a full multiple market and non-market time use activity model can be formulated which will overcome the traditional one-sided focus on paid work alone.

The theoretical modeling approach allows for the formulation of the impacts of changing model parameters (like the income and substitution effects of a price/wage change). However, only an empirically based estimation and explanation with proven socioeconomic hypotheses will finally quantify these effects and decide, for example, whether the income or the substitution effect will be dominant - an important result about incentives in explaining e.g. the final labour supply (see e.g. Merz, 1990).

To do this, detailed time use information on multiple activities is necessary. However, again, representative individual personal and household demographics are essential for a sound empirically based result.

\subsection{Policy impacts of the tax and transfer system - time allocation effects on the formal and informal economy by microsimulation modeling}

Explaining behaviour is the basis for a targeted economic and social policy. To analyse policy impacts of a tax and transfer system the microsimulation approach has been proven as a well suited instrument for such impact analyses on an individual/family/household level (Mitton, Sutherland and Weeks, 2000; Citro and Hanushek, 1999a,b; Harding ,1996; Merz, 1991a; Orcutt, Merz and Quinke, 1986).

In contrast to microsimulation analyses of typical cases, representative microsimulation approaches rely on representative samples. Microsimulation approaches based on representative samples with time use focus on market and non-market activities were used for instance by Merz (1996a) or Merz (1991b) and Merz and Wolff (1993) for German tax reform impacts on the formal and informal economy or Flood (1988) for Swedish tax reform impacts. Questions 
concerning incentives of a tax reform via changing time used for paid work within such a microsimulation frame need a solid demographic background of persons and households.

To summarise: for testing given time use models, finding new explanations and policy impact analyses of individual time use behaviour within the household/family context - based either on a microeconomic or further psychological, sociological etc. theory - appropriate sociodemographics are an ultimate requirement. To fulfill this requirement, the calibration procedure has to incorporate the discussed personal and household/family information to ensure a valid demographic frame which forms the basis for substantial research and content driven analyses.

\section{$4 \quad$ The calibration of time use diary days}

Time use diaries provide their information over one or more days. It is expected that one will observe different time use patterns on different days of a week, a month, a year etc. (like summer vs. winter, workdays vs. weekends, public holidays or not etc.). Usually time use diaries are asked for two or three days in principle by a random procedure to cover all days over a week and year. However and again, due to unit non-response/missing data, sampling failures etc. almost every time the final available sample is not an ideal random sample with respect to all periods/day types considered.

Thus, in addition to the demographic structure, the proper distribution of diary days itself (e.g. days over the week, weekend or the season of the survey) has to be considered in a calibration procedure as well.

For example, if we have a survey with two diary days of the respondents, the following daily adjustments could be used: $8 / 7$ th for normal workdays [Monday thru Thursday], 2/7th Fridays, 2/7th Saturdays and 2/7th Sundays adding up to 14/7th or 2 days.

These adjustment factors are similar to economic multipliers/inflators used in microsimulation modeling, which in principle could be used before, within, or after a simultaneous demographic re-weighting. If it is used before, then the previous given demographic adjustment factors are altered and the altered factors are part of the simultaneous approach, but only via the old weights in the distance function. If it is used after a simultaneous re-weighting, the direct interdependencies are lost. We therefore prefer to incorporate the diary days directly within the simultaneous re-weighting by catching the socio-economic and daily interdependencies in a comprehensive way. 


\section{$5 \quad$ Assessing and new calibration of the American Heritage Time Use Data (AHTUD)}

The collection of time use data has been recently spurred by the desire to obtain data necessary for understanding the full productive inputs and outputs of societies. However, the validity, reliability and comparability dimensions of these data have only sporadically been addressed. As mentioned, valid and reliable individual time use data, in connection with a proper set of background variables, are essential elements of an empirical foundation and evaluation of existing theories, and for the search of new empirical-based hypotheses about individual time use behaviour in the household context .

Our international project Assessing Time Use Survey Datasets is an examination of critical aspects of the time-diary variables, codes, and background demographic data required to provide inputs to a non-market household account. Within this project several potentially useful individual US time use heritage datasets were identified for use in developing a historical series of non-market accounts (St. Croix and Harvey, 2005). ${ }^{5}$ In order to evaluate the series of American Heritage Time Use Studies (AHTUD) (1965, 1975, 1985, 1992-94, 1998-99) the following analyses investigates the representativeness of this data and provides a new harmonised calibration for sound time use analyses.

\section{American Heritage Time Use Data}

The following studies were identified and are the subject of the present investigation:

- 1965: Multi-national study: United States

Robinson, J.P. (1977), How Americans used time in 1965, Institute for Social Research, University of Michigan, Ann Arbor, Michigan

- 1975: Time use in economic and social accounts, 1975-1976: United States

Juster, T.F., Hill, M.S., Stafford, F.P. and J. Eccles Parsons (1983). 1975-1981 Time Use Longitudinal Panel Study, Survey Research Center, Institute for Social Research, University of Michigan, Ann Arbor, Michigan

- 1985: Americans' use of time

Robinson, J.P. (1985), Americans' use of time, Survey Research Center, College Park, MD: University of Maryland,

1985c: Americans' use of time

as above but created from mail episodes (see St. Croix and Harvey, 2005)

- 1992: EPA time use survey, 1992-1994: United States

Triplett, T. (1995), Data collection methods report for estimating exposure to pollutants

For further data work on the American Heritage Time Use surveys and the resulting edited files see the mentioned activities of the Centre for Time Use Research (CTUS) at the University of Oxford and their American Heritage Time Use Study (AHTUS) at www.timeuse.org/ahtus. 
through human activity pattern data, A national micro-behavioural approach, Survey Research Center, College Park, MD: University of Maryland

- 1998: Family interaction, social capital, and trends in time use, 1998-1999: United States Robinson, J.P., Bianchi, S.M.and S. Presser (1999), Family interaction, social capital, and trends in time use, 1998-1999, Survey Research Center, College Park, MD: University of Maryland

Details of each survey are listed in the Table 1. A comprehensive description and evaluation of these American time use studies is given in St. Croix and Harvey (2005).

Time use theory based and harmonised calibration for all AHTUD files

As our further results will show, the existing calibration within each separate AHTUD file delivers seriously biased calibration results. The developing of a new AHTUD calibration will improve subsequent research for four major reasons:

First, for substantial analyses it is important that fundamental socio-demographic variables meet the given aggregates of reliable demographic data such as the current population survey (CPS) or the Intercensal Population Estimates of the U.S. Census Bureau; thus, the existing calibration bias in each AHTUD has to be erased.

Second, for longitudinal comprehensive time use analyses with the entire set of AHTUD files it is important to have a harmonised calibration approach of each AHTUD file, both, with respect to the content of the aggregates to be achieved and the calibration procedure itself. Working with harmonised calibrated data will allow sensitivity analyses and disentangling demographic changes vs. time use behaviour changes.

Third, because of a non-random distribution of time use data itself (like diary days within a week) an appropriate calibration is required.

Fourth and overall, the new harmonised AHTUD calibration will be content driven, providing sound and representative further substantive analyses of individual time use behaviour.

Aggregate characteristics for the AHTUD files

Our selection of calibration variables and respective aggregates to be achieved follows the above discussed dimensions and requirements by considering the relevant U.S. population, the content driven socio-demographic background with personal and household/family characteristics and sampling features concerning the diary date distribution.

The sample size and the nature of each calibration algorithm limit the amount of multiple restrictions given limited number of observations in respective subgroups and the larger factor variance arising from many restrictions.

Last but not least, the data has to be available (and in a similar manner) in the sample files as well as in the CPS-files (providing totals) for all of the specified years. When dealing with five samples simultaneously, the selection of the optimal set of restrictions is difficult and may vary from one which would have been chosen for a single calibration. Finding a com- 
promise among the desired detail of restrictions, practical requirements, and the availability of data in all sample-files is a challenging task.

Considering the mentioned limitations and eligible structural variables in the AHTUD files available for an adjustment to CPS key data, the following calibration/adjustment characteristics were chosen:

- Age (5-year-classes) crossed by gender

- Educational attainment

- Occupational status (full time/part time/unemployed, self-employed)

- Marital status (single/married/divorced/widowed)

- Number of children (below 18 years of age) living in household

- Day of the week (for a representative distribution of diary days)

These adjustment characteristics are the core of and in line with many other international time use calibration aggregates like the Dutch Time Use Study from 1997 (CBS, 1999) ${ }^{6}$, the UK Time Use Study 2001, ${ }^{7}$ or the German Time Use Survey 2001/2002 (Ehling and Bieber, 2003). ${ }^{8}$ For a further discussion of appropriate adjustment characteristics also see Harvey, Elliott and Procos (1977).

The intercensal population estimates of the US Census Bureau ${ }^{9}$ provides the population totals. Due to the size and structure of the sample, classes with a width of five years were used. As the samples do not cover persons younger than 18 years, the first age class represents only persons of 18 and 19 years. The educational attainment is available via the "school attainment" variable ${ }^{10}$ in the current population survey. However, only people over 25 years of age are represented in these statistics, which must be considered when building the microdatamatrix from the AHTUD files. The occupational status can be covered with data from the Bureau of Labour Statistics ${ }^{11}$ surveyed in the CPS. Unfortunately, the time series started three years too late, with the year 1968, so for the 1965 time use survey aggregate data of 1968 must be used.

6 With calibration totals sex by age, marital status, social position, degree of urbanization, household composition, and that the day of the week occurs regularly often (Dutch Time Use Study 1997).

7 With two sets of population controls: age group [8-11, 12-15, 16-19, 20 (5) -74, 75 and over] by gender, and Government Office Regions plus Scotland, Wales, Northern Ireland.

8 With age by sex, social status, occupation by sex, household size, household type, community type, where all items are respective to the regional division by the 16 Bundesländer. Additionally the type of weekdays is considered.

$9 \quad$ U.S. Census Bureau. (n.d.a).; U.S. Census Bureau. (n.d.b); U.S. Census Bureau. (n.d.c).

10 U.S. Census Bureau. (2005).

11 The tables are created with the LABSTAT- Database using following codes: LNU02500000, LNU02600000, LNU05000000. 
To build the aggregates for the marital status, Labstat data was used ${ }^{12}$ again. The labour statistics only include people older than 16 years of age, but this restriction will not affect the aggregates for occupational-status or marital-status, and the AHTUD files do not include respondents younger than 16 years. The number of children living in the household corresponds to the information on "living arrangements of children under 18 years" provided by the CPS. ${ }^{13}$ In this case as well, there was no information available for 1965, so numbers of 1968 had to be used.

To enhance the structural data by a representative distribution of diary days, the days of the week were taken into account. As public holidays ${ }^{14}$ (see Appendix Table 1) will affect the time use-behaviour of the respondents, these were counted in a class together with the Sundays. Calibrating days, the aggregate to be achieved for a certain year is given by weekday margin $=(($ number of weekdays $) / 365) *$ total population size $(\mathrm{N})$ and similar for Sundays and public holidays as sunday/public holiday margin $=(($ number of Sundays or public holidays)/365)*total population size (N). Appendix Table A2 for every year provides the number of weekdays and Sundays/public holidays only. To avoid linear dependency, one weekday without loss of generality - has to be neglected. This reference is Saturday.

Table 2 finally shows all aggregates (restrictions) to be achieved for all five AHTUD files. The Appendix Table A2 connects these totals with the respective variables of the five AHTUD files.

\section{Results: New harmonised calibration of the AHTUD files}

The calibration procedure itself was computed with our software package ADJUST version 1.1.8, developed at the Research Institute on Professions (FFB) at the Leuphana University of Lüneburg, Germany (http://ffb.uni-lueneburg.de/adjust). Based on the above harmonised calibration characteristics of Tables 2 and A2 describing the restrictions (vector $r$ with $m=36$ simultaneous characteristics) and the sample matrix $\mathrm{S}$ ) the calibration based on the Minimum Information Loss (MIL) Principle finally provides the single adjustment weights for each microunit and for each AHTUD file.

As the restriction characteristics age and gender are exhaustive, one characteristic of each category had to be left out respectively to avoid linear dependencies. Unfortunately, no data on the marital status was collected in the 1992-94 survey, so this category could not be included in the calibration for that year. Whenever possible, available weights were used to initialise the calibration procedure. These former weights all summed up only to its sample size and have to be multiplied by a constant factor for the final overall population size.

12 For the years '65 to '85: EmplymtStatus by_Maritalstatus.pdf Bureau of Labour Statistics; Labour Force Statistics Derived from the Current Population Survey, 1948-87; Bulletin 2307; August 1988; for the years after 1992-1998 the LABSTAT-Database with following codes: LNU000149, LNU000314, LNU000150, LNU000315, LNU000151, LNU000316.

13 U.S. Census Bureau. (2004).

14 U.S. Code Title 5, part II, Subpart E, Chapter 61, Subchapter I, §6103. 
Since only valid cases of entire availablilty can be used for the calibration, some cases could not be included in the calibration due to missing values. However, as our categories were selected carefully, only small numbers of those cases occurred in the different studies. In the 1965 data set, 2,014 valid cases were used for the calibration, and only 7 cases with missing values had to be dropped. In the 1975 data set, there were no missing values and all 2,406 cases could be used for the calibration. For the survey 10 years later, in 1985, 4,467 valid and 473 missing cases occurred. In the 1992-94 file 7,297 valid cases can be found and 217 missing. In the 1998-99 time use data file 1,142 valid and 9 missing cases were listed.

In addition to the missing cases, in two calibration procedures (for 1975 and 1998), restriction number 34 (College Graduate) had to be removed due to linear dependencies. For those two files the mentioned restriction was taken into the reference group of the category 'school attainment', as otherwise linear dependency would be given. The remaining characteristics are available for all five AHTUD files.

The 1975 file contains information about four waves of spouse's and respondent's time use. Our calibration considers the respondents and spouses both as individuals with a proper demographic representation, even the household characteristics (e.g. the number of children are respected properly). For comparison reasons we only calibrate wave one with correct diary days' full year distribution. However, if all four waves together will be investigated, then the demographic adjustment out of wave one has to be adjusted by maximal ${ }^{15}$ four times having the same person. Then, in addition, the calibration of the days of the week for a representative distribution of diary days from all four waves must be re-computed.

As the starting weights provided by the original heritage files reflect the possible quotas of the different sub samples and - as mentioned - sum up only to its sample size, we multiplied them by a constant factor to achieve the population size. These multiplied weights - further called old weights - are used to build the sample aggregates of the five heritage files before our new calibration.

Table 3 shows the differences of the respective actual population size to the aggregates before the new calibration of the five heritage files from 1965, 1975, 1985, 1992-94, 1998-99. The single differences are the relative deviation of the aggregates using the former (old) weights compared to the CPS population to be achieved. A negative value, say $-15 \%$, indicates an under-representation by $15 \%$ compared to the actual respective US population size when using the former weights. The respective under-representation or over-representation totally vanishes with our new calibration weights.

15 Missing values will yield less than four waves' information. 
Table 1

American Heritage Time Use Data (AHTUD) under investigation

\begin{tabular}{|c|c|c|c|c|c|}
\hline & $\begin{array}{c}\text { United States, } \\
1965-66\end{array}$ & $\begin{array}{l}\text { United States, } \\
\text { 1975-76 } \\
\text { (Wave 1) }\end{array}$ & $\begin{array}{l}\text { United States, } \\
1985\end{array}$ & $\begin{array}{l}\text { United States, } \\
\text { 1992-94 EPA }\end{array}$ & $\begin{array}{c}\text { United States, } \\
1998-99\end{array}$ \\
\hline Sampling unit & Individual & Individual and spouse & Individual and household & Individual & Individual \\
\hline $\begin{array}{l}\text { Population not in sam- } \\
\text { pling frame }\end{array}$ & $\begin{array}{l}\text { Families where all mem- } \\
\text { bers worked as farmers, } \\
\text { residents of Hawaii and } \\
\text { Alaska }\end{array}$ & Institutional population & $\begin{array}{l}\text { Institutional population, } \\
\text { households without tele- } \\
\text { phones }\end{array}$ & $\begin{array}{l}\text { Persons not living in } \\
\text { private residences }\end{array}$ & $\begin{array}{l}\text { Institutional population, } \\
\text { households without tele- } \\
\text { phones }\end{array}$ \\
\hline $\begin{array}{l}\text { Number of respon- } \\
\text { dents }\end{array}$ & 2,021 persons & $\begin{array}{c}2,406 \text { persons } \\
(1,346 \text { completed all four } \\
\text { diaries })\end{array}$ & $\begin{array}{c}4,940 \text { persons }(5,358 \text { if } \\
\text { diaries for individuals } \\
\text { aged } 12-17 \text { are included })\end{array}$ & $\begin{array}{c}9,386 \text { persons }(7,514 \\
\text { adults })\end{array}$ & 1,151 persons \\
\hline Age of respondent & 19 to 65 years of age & $18+$ & $12+$ & Any age & $18+$ \\
\hline Response rate & $\begin{array}{c}82 \% \text { for Jackson sample; } \\
74 \% \text { for all other cities }\end{array}$ & $\begin{array}{l}72 \% \text { responded to initial } \\
\text { request; } 44.9 \% \text { completed } \\
\text { all four diaries }\end{array}$ & $\begin{array}{c}51 \% \text { mail-backs }(3,340), \\
67 \% \text { telephone interviews } \\
(1,210), 60 \% \text { face to face } \\
\text { interviews }(808), 55.2 \% \\
\text { overall }\end{array}$ & $63 \%$ & $56 \%$ \\
\hline
\end{tabular}

Source: St. Croix and Harvey 2005. 
Joachim Merz and Henning Stolze: Representative time use data and new harmonised calibration of the American Heritage Time Use Data (AHTUD) 1965 - 1999

Table 2

Aggregates to be achieved for the different AHTUD files

\begin{tabular}{|c|c|c|c|c|c|c|c|}
\hline Category & $\begin{array}{c}\text { Restriction } \\
\text { number }\end{array}$ & Description & 1965 & 1975 & 1985 & 1993 & 1998 \\
\hline \multirow[t]{12}{*}{ Male \# age } & 01 & male, age $18-19$ & 3.804 .236 & 4.232 .884 & 3.841 .017 & 3.570 .727 & 4.053 .326 \\
\hline & 02 & male, age $20-24$ & 6.899 .289 & 9.838 .857 & 10.670 .549 & 9.506 .702 & 9.040 .112 \\
\hline & 03 & male, age $25-30$ & 5.612 .436 & 8.617 .480 & 10.887 .657 & 9.718 .386 & 9.202 .990 \\
\hline & 04 & male, age $31-34$ & 5.517 .566 & 7.017 .543 & 10.019 .185 & 11.069 .951 & 9.922 .383 \\
\hline & 05 & male, age 35-39 & 5.898 .942 & 5.702 .224 & 8.797 .913 & 10.779 .896 & 11.253 .107 \\
\hline & 06 & male, age $40-44$ & 6.058 .104 & 5.496 .967 & 6.964 .647 & 9.550 .162 & 10.886 .210 \\
\hline & 07 & male, age $45-49$ & 5.552 .528 & 5.712 .160 & 5.699 .630 & 7.907.584 & 9.312 .659 \\
\hline & 08 & male, age $50-54$ & 5.101 .484 & 5.737 .247 & 5.253 .668 & 6.274 .160 & 7.734 .322 \\
\hline & 09 & male, age 55-59 & 4.582 .681 & 5.047 .753 & 5.320 .599 & 5.153 .959 & 6.040 .932 \\
\hline & 10 & male, age 60-64 & 3.583 .081 & 4.368 .044 & 5.053 .423 & 4.781 .116 & 4.884 .251 \\
\hline & 11 & male, age 65-69 & 2.972 .192 & 3.596 .151 & 4.206 .036 & 4.508 .024 & 4.375 .310 \\
\hline & 12 & male, age 70+ & 5.041 .923 & 5.669 .334 & 7.259 .226 & 8.867 .436 & 9.858 .514 \\
\hline \multirow[t]{8}{*}{ Female \# age } & 13 & female, age 18-19 & 3.672 .040 & 4.063 .067 & 3.730 .063 & 3.401 .195 & 3.852 .206 \\
\hline & 14 & female, age $20-24$ & 6.847 .150 & 9.687 .979 & 10.477 .262 & 9.195 .636 & 8.720 .108 \\
\hline & 15 & female, age $25-30$ & 5.727 .774 & 8.662 .876 & 10.854 .516 & 9.698 .740 & 9.295 .932 \\
\hline & 16 & female, age 31-34 & 5.607 .221 & 7.173 .363 & 10.148 .768 & 11.158 .397 & 10.096 .947 \\
\hline & 17 & female, age 35-39 & 6.121 .742 & 5.931 .446 & 9.041 .560 & 10.909 .318 & 11.364 .160 \\
\hline & 18 & female, age $40-44$ & 6.368 .258 & 5.700 .193 & 7.220 .447 & 9.790 .668 & 11.086 .204 \\
\hline & 19 & female, age 45-49 & 5.827 .607 & 6.072 .202 & 5.959 .224 & 8.205 .987 & 9.668 .866 \\
\hline & 20 & female, age $50-54$ & 5.357 .560 & 6.235 .032 & 5.615 .061 & 6.633 .198 & 8.167 .797 \\
\hline
\end{tabular}


Joachim Merz and Henning Stolze: Representative time use data and new harmonised calibration of the American Heritage Time Use Data (AHTUD) 1965 - 1999

Table 2 (cont.)

Aggregates to be achieved for the different AHTUD files

\begin{tabular}{|c|c|c|c|c|c|c|c|}
\hline Category & $\begin{array}{c}\text { Restriction } \\
\text { number }\end{array}$ & Description & 1965 & 1975 & 1985 & 1993 & 1998 \\
\hline \multirow[t]{4}{*}{ Female \# age } & 21 & female, age 55-59 & 4.922 .336 & 5.598 .004 & 5.889 .797 & 5.598 .891 & 6.539 .782 \\
\hline & 22 & female, age $60-64$ & 3.988 .792 & 5.031 .207 & 5.849 .526 & 5.404 .942 & 5.455 .166 \\
\hline & 23 & female, age 65-69 & 3.578 .099 & 4.536 .199 & 5.189 .190 & 5.501 .735 & 5.171 .407 \\
\hline & 24 & female, age $70+$ & 6.859 .179 & 8.894 .611 & 11.937 .666 & 14.076 .548 & 15.040 .033 \\
\hline Children & 25 & children $<18$ years in $\mathrm{HH}$ & $68.362 .000^{*}$ & 64.317 .000 & 60.784 .000 & 65.053 .000 & 68.419 .000 \\
\hline \multirow[t]{2}{*}{ Marital status } & 26 & married & 84.734 .000 & 96.222 .000 & 102.217 .000 & 109.196 .000 & 112.552 .000 \\
\hline & 27 & single (never married) & 31.945 .000 & 33.682 .000 & 44.042 .000 & 49.334 .000 & 53.939 .000 \\
\hline \multirow{2}{*}{$\begin{array}{l}\text { Occupational } \\
\text { status }\end{array}$} & 28 & full-time employed & $65.216 .000^{*}$ & 72.393 .000 & 89.201 .000 & 99.698 .000 & 108.770 .000 \\
\hline & 29 & part-time employed & $11.148 .000^{*}$ & 14.767 .000 & 19.226 .000 & 21.691 .000 & 23.655 .000 \\
\hline \multirow{5}{*}{$\begin{array}{l}\text { Educational } \\
\text { attainment }\end{array}$} & 30 & none/ only elementary & 34.045 .000 & 25.545 .000 & 19.893 .000 & 15.127 .000 & 12.782 .000 \\
\hline & 31 & some high school & 18.617 .000 & 18.237 .000 & 17.553 .000 & 17.067 .000 & 16.776 .000 \\
\hline & 32 & high school grad. & 31.703 .000 & 42.353 .000 & 54.866 .000 & 57.589 .000 & 58.174 .000 \\
\hline & 33 & some college & 9.139 .000 & 14.518 .000 & 23.405 .000 & 37.451 .000 & 42.506 .000 \\
\hline & 34 & college grad. or more & 9.742 .000 & 16.244 .000 & 27.808 .000 & 35.590 .000 & 41.973 .000 \\
\hline \multirow[t]{2}{*}{ Weekday } & 35 & normal working day** & 199 & 200 & 199 & 200 & 201 \\
\hline & 36 & Sunday or public holiday** & 62 & 62 & 62 & 62 & 62 \\
\hline
\end{tabular}

Data available for 1968 only. ** Occurrences as in the specified year. For calibration the person-days in the U.S. population represented by the sample will be used instead.

Source: Various US CPS information (see text); own arrangement. 
Table 3

Calibration situation before the new harmonised calibration: Differences to the actual aggregates

\begin{tabular}{|c|c|c|c|c|c|c|c|c|}
\hline \multirow{2}{*}{ Category } & \multirow{2}{*}{$\begin{array}{c}\text { Restr. } \\
\text { no. }\end{array}$} & \multirow{2}{*}{ Description } & \multicolumn{6}{|c|}{ Differences to actual aggregates [\%] } \\
\hline & & & 1965 & 1975 & 1985 & $1985 \mathrm{c}$ & 1993 & 1998 \\
\hline \multirow[t]{12}{*}{ Male \# age } & 01 & male, age $18-19$ & -69.9 & -59.2 & -19.4 & -31.6 & -72.5 & -46.9 \\
\hline & 02 & male, age $20-24$ & 25.8 & -22.4 & -7.4 & -19.7 & -73.2 & -14.6 \\
\hline & 03 & male, age $25-30$ & 31.3 & -8.7 & -14.8 & -9.8 & -59.4 & 22.8 \\
\hline & 04 & male, age $31-34$ & -14.2 & -4.1 & -6.1 & -8.2 & -59.8 & 2.5 \\
\hline & 05 & male, age $35-39$ & 4.7 & 23.1 & -8.4 & 4.5 & -50.0 & -12.2 \\
\hline & 06 & male, age $40-44$ & 18.5 & 15.2 & -6.2 & -12.0 & -36.3 & -10.6 \\
\hline & 07 & male, age 45-49 & 17.1 & -18.8 & -19.5 & -4.5 & 19.8 & 9.9 \\
\hline & 08 & male, age $50-54$ & 11.7 & -12.2 & 1.5 & 2.4 & 45.5 & -3.4 \\
\hline & 09 & male, age 55-59 & 0.5 & 5.6 & -10.3 & -9.4 & 88.9 & -7.3 \\
\hline & 10 & male, age $60-64$ & 5.7 & -20.3 & 8.8 & -9.6 & 126.2 & -1.0 \\
\hline & 11 & male, age $65-69$ & -67.7 & 37.5 & -1.8 & -6.3 & 110.6 & 28.3 \\
\hline & 12 & male, age $70+$ & -87.1 & -31.8 & 30.5 & 53.4 & 25.3 & -36.0 \\
\hline \multirow[t]{12}{*}{ Female \# age } & 13 & female, age $18-19$ & -30.2 & -9.2 & -4.5 & -1.0 & -65.3 & 31.8 \\
\hline & 14 & female, age $20-24$ & 43.0 & -15.6 & -5.8 & -11.6 & -50.8 & -13.5 \\
\hline & 15 & female, age $25-30$ & 17.8 & 4.3 & -6.9 & 0.3 & -48.0 & -2.8 \\
\hline & 16 & female, age $31-34$ & 29.8 & 10.0 & 13.9 & 3.6 & -52.5 & 10.6 \\
\hline & 17 & female, age 35-39 & 15.5 & 15.1 & 16.2 & 13.5 & -46.3 & -1.6 \\
\hline & 18 & female, age $40-44$ & 31.8 & -4.6 & -10.4 & 1.4 & -14.1 & 18.4 \\
\hline & 19 & female, age $45-49$ & 16.7 & -8.8 & 14.6 & 18.6 & 17.4 & -7.8 \\
\hline & 20 & female, age 50-54 & 30.7 & -12.8 & -1.6 & 7.0 & 74.1 & -19.8 \\
\hline & 21 & female, age 55-59 & 13.0 & -14.1 & 31.0 & 5.2 & 146.2 & -13.4 \\
\hline & 22 & female, age 60-64 & -2.4 & 7.9 & -6.6 & -9.1 & 143.6 & -2.2 \\
\hline & 23 & female, age 65-69 & -68.7 & -0.1 & -5.9 & -19.2 & 100.1 & -26.1 \\
\hline & 24 & female, age $70+$ & -86.7 & -31.6 & 40.9 & 20.0 & -18.2 & -17.5 \\
\hline \multirow[t]{2}{*}{ Children } & & children & & & & & & \\
\hline & 25 & $<18$ in $\mathrm{HH}$ & 150.1 & 148.0 & 89.4 & 75.1 & 127.9 & 156.2 \\
\hline \multirow[t]{3}{*}{ Marital status } & 26 & married & 9.8 & 18.0 & 7.4 & 8.5 & $\mathrm{n} / \mathrm{a}$ & 6.5 \\
\hline & & single & & & & & & \\
\hline & 27 & (never married) & -36.6 & -58.1 & -23.9 & -18.5 & $\mathrm{n} / \mathrm{a}$ & -30.6 \\
\hline \multirow{2}{*}{$\begin{array}{l}\text { Occupational } \\
\text { status }\end{array}$} & 28 & full-time employed & 13.5 & 7.9 & 22.8 & 4.0 & 9.3 & 9.3 \\
\hline & 29 & part-time employed & -40.2 & -26.3 & 4.8 & -12.8 & -0.7 & -6.4 \\
\hline
\end{tabular}


Table 3 (cont.)

Calibration situation before the new harmonised calibration: Differences to the actual aggregates

\begin{tabular}{|c|c|c|c|c|c|c|c|c|}
\hline \multirow{2}{*}{ Category } & \multirow{2}{*}{$\begin{array}{c}\text { Restr. } \\
\text { no. }\end{array}$} & \multirow{2}{*}{ Description } & \multicolumn{6}{|c|}{ Differences to actual aggregates [\%] } \\
\hline & & & 1965 & 1975 & 1985 & $1985 \mathrm{c}$ & 1993 & 1998 \\
\hline \multirow{6}{*}{$\begin{array}{l}\text { Educational } \\
\text { attainment }\end{array}$} & & none/ only & & & & & & \\
\hline & 30 & elementary & -19.5 & -14.7 & 1.4 & -42.8 & -76.6 & -27.8 \\
\hline & 31 & some high school & 8.8 & -0.4 & 4.5 & -21.9 & -28.0 & 4.4 \\
\hline & 32 & high school grad. & 11.5 & 2.1 & 6.7 & 13.0 & 10.2 & -2.6 \\
\hline & 33 & some college & -16.6 & -6.3 & -1.7 & 0.8 & 18.2 & 0.4 \\
\hline & 34 & $\begin{array}{c}\text { college grad. } \\
\text { or more }\end{array}$ & -33.9 & $\mathrm{n} / \mathrm{a}$ & -39.2 & -15.2 & 41.9 & $\mathrm{n} / \mathrm{a}$ \\
\hline \multirow[t]{3}{*}{ Weekday } & & normal & & & & & & \\
\hline & 35 & working day & 2.0 & 9.3 & 5.5 & 7.1 & 6.6 & 2.1 \\
\hline & 36 & $\begin{array}{c}\text { Sunday or } \\
\text { public holiday }\end{array}$ & -18.5 & 11.5 & -7.4 & -33.6 & 14.9 & -11.8 \\
\hline $\mathrm{n}$ & & & 2014 & 2406 & 4560 & 2811 & 7297 & 1142 \\
\hline
\end{tabular}

Note, for 1985 there were two files: 1985: Americans' Use of Time, Robinson, John P. (1985), 1985c: Americans' Use of Time but created from mail episodes (St. Croix and Harvey 2005).

Source: American Heritage Time Use Survey (AHTUD) files, own computations.

The overall result before calibration: The differences between the totals in the old survey weights and the respective actual population (representation bias) are remarkable. There is a serious socio-demographic bias when the former weights are used for calibration with respect to the chosen content driven calibration characteristics. This representation bias indeed is in need of a new calibration - such as ours - to eliminate these differences in order to achieve representative results for further substantive studies.

The following figures provide in-depth information about this representation bias with respect to different characteristics.

Figures 1 to 2 show the representation bias according to the old weights for male and female age classes and for all AHTUD files. It will be evident that younger and older persons, regardless of their gender, show the most differences in the desired actual totals. The 1993 Time Use Survey, in particular, is the time use study with the most calibration bias for peoples 50 years and older for males and females.

All AHTUD files seem to have a focus on families or at least on married couples: the respective old household/family weights fit the actual totals fairly well (Figure 3). Singles are under-represented (not 1993). All AHTUD surveys, however, show high over sampling rates for children living in the household/family, which in particular can produce misleading results in time use studies where children - and therefore the family composition - play an important role. 


\section{Figure 1}

Representation of American Heritage Time Use Files 1965 - 1998/99 - Over- and underrepresentation compared to actual totals in \%: Males by age classes

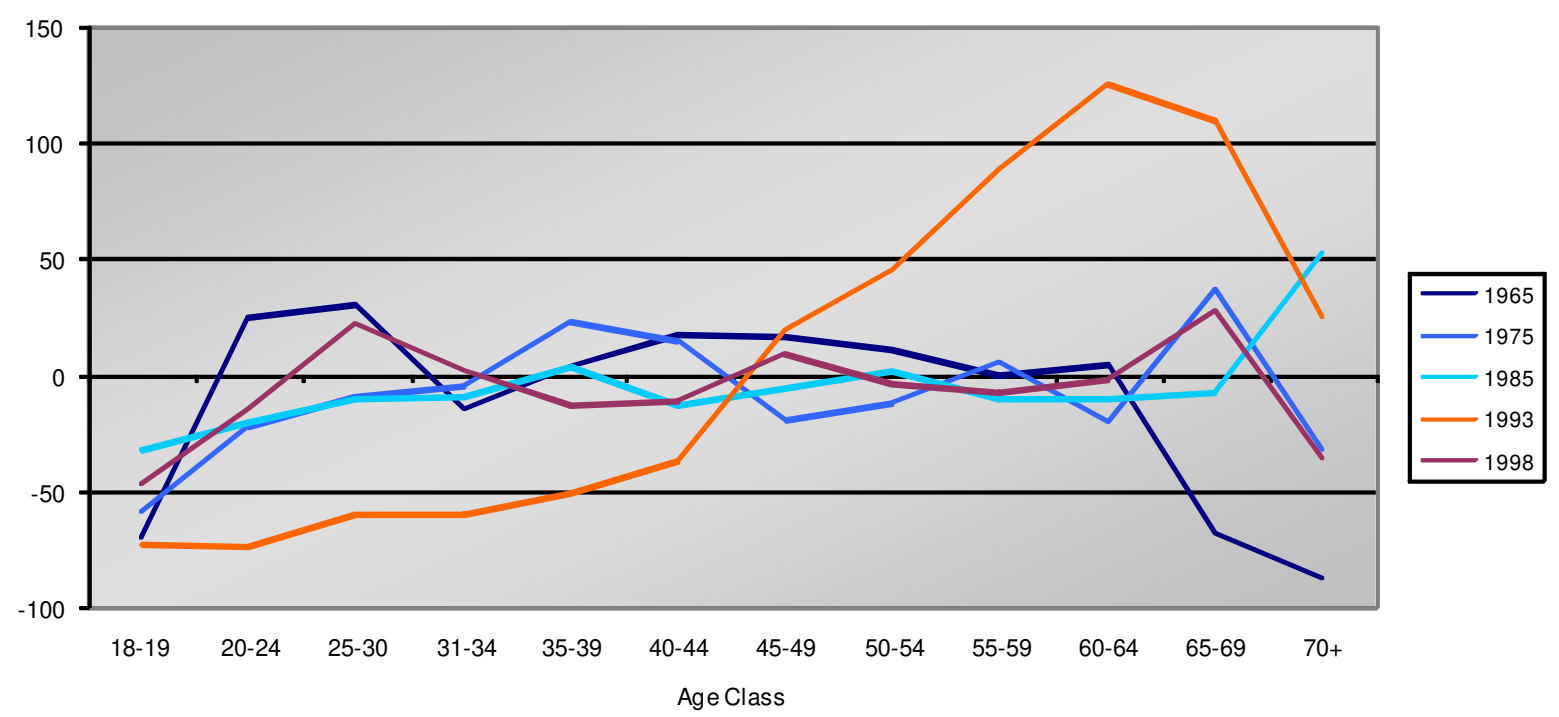

Source: American Heritage Time Use Files 1965 - 1998/99, own computation.

\section{Figure 2}

Representation of American Heritage Time Use Files 1965 - 1998/99 - Over- and underrepresentation compared to desired totals in \%: Females by age classes

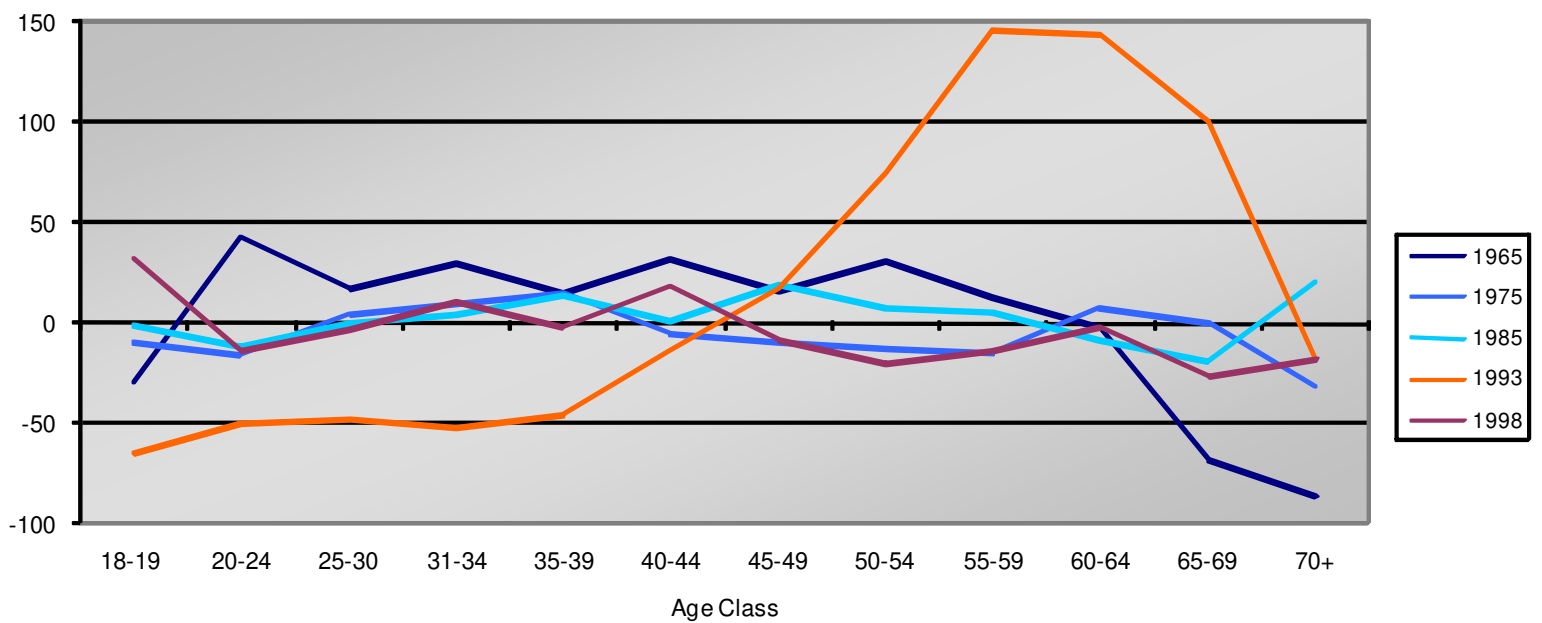

Source: American Heritage Time Use Files 1965 - 1998/99, own computation.

According to educational attainment the representation bias is most evident in the 1965 survey with underrepresentation in a lower and upper educational attainment (Figure 4). Additionally, strong effects are within the 1993 time use survey, with an underrepresentation in a lower education, resulting in an obvious overrepresentation of higher educated persons. 
Figure 3

Representation of American Heritage Time Use Files 1965 - 1998/99 - Over- and underrepresentation compared to desired totals in \%: Family status

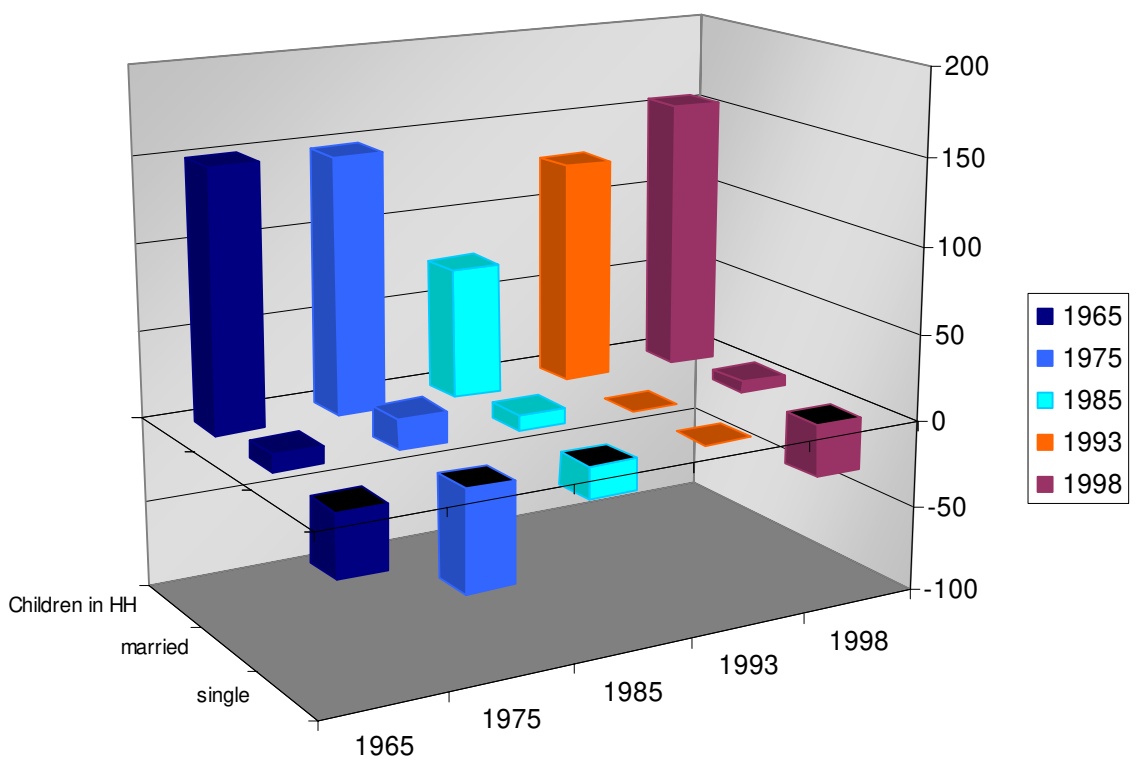

Source: American Heritage Time Use Files 1965 - 1998/99, own computation.

Figure 4

Representation of American Heritage Time Use Files 1965 - 1998/99 - Over- and underrepresentation compared to actual totals in \%: Educational attainment

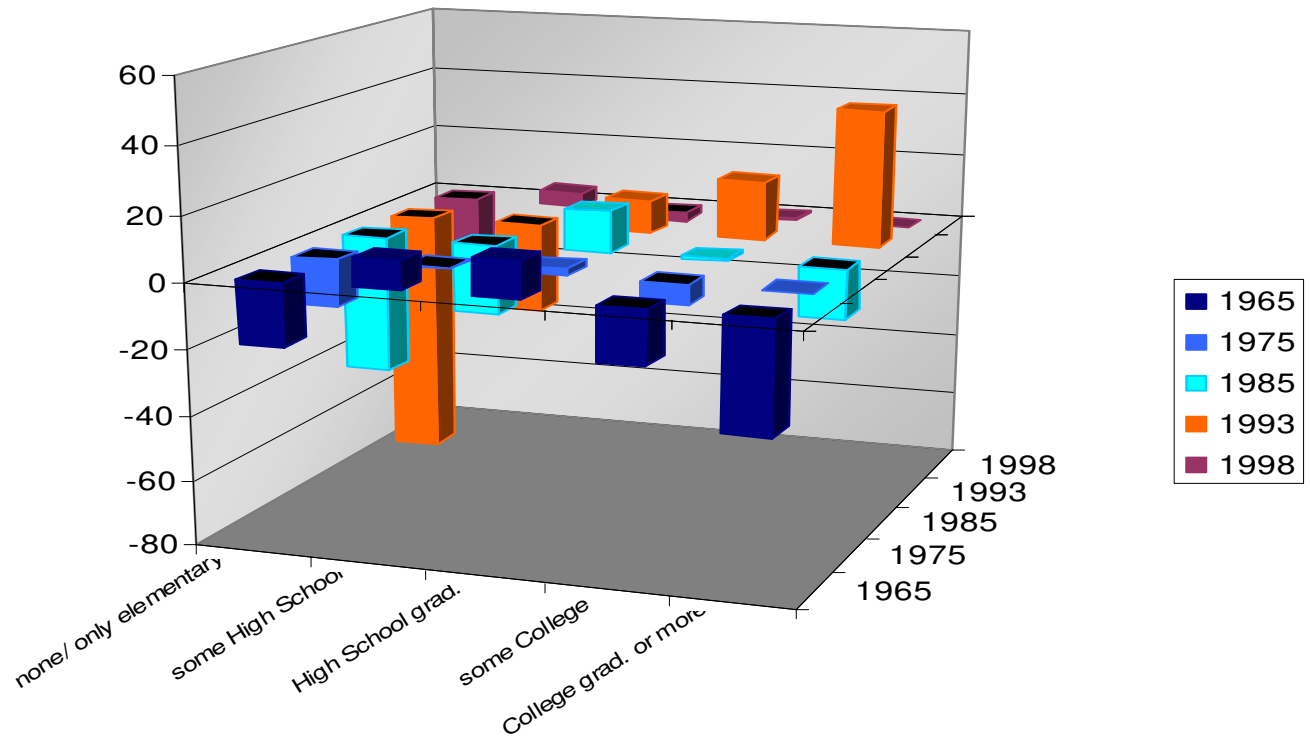

Source: American Heritage Time Use Files 1965 - 1998/99, own computation.

With regard to the occupational status in particular for part-time employment and within the early AHTUD files, in particular, underrepresentation will be evident (Figure 5). Since the occupational status is important for any income and paid work situation, the old weights again result in a biased situation. 


\section{Figure 5} Representation of American Heritage Time Use Files 1965 - 1998/99 - Over- and
underrepresentation compared to actual totals in \%: Occupational Status

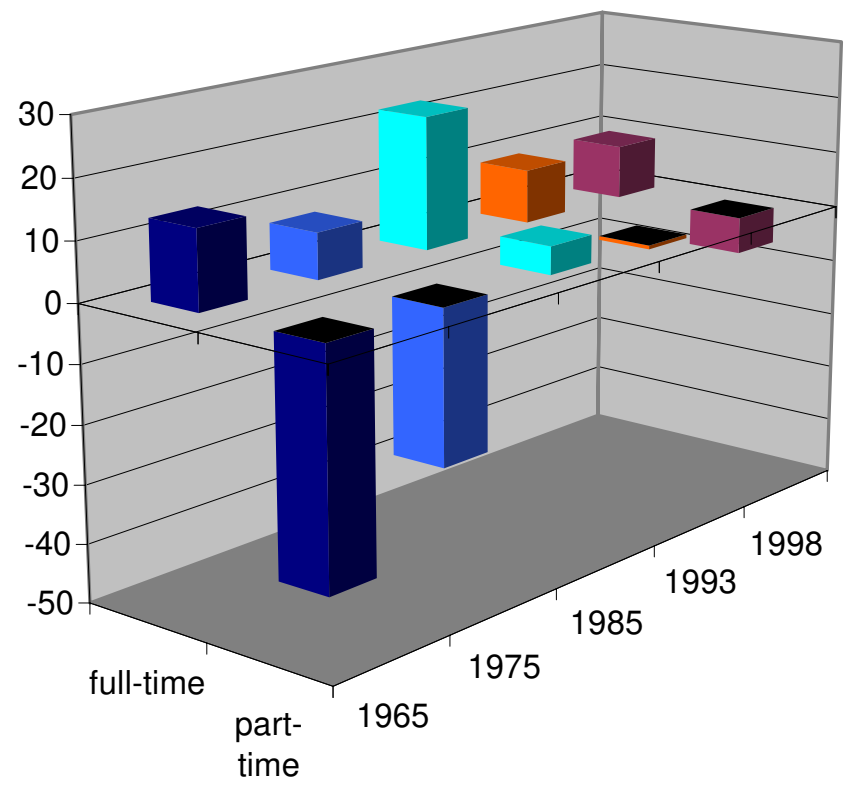

Source: American Heritage Time Use Files 1965 - 1998/99, own computation.

The variations concerning the weekdays are interesting; the consideration of the public holidays in the 1998-file causes an overrepresentation of $3.4 \%$ for the working days and an under-representation of $-17.4 \%$ for the Sundays and public holidays. It is likely that this heritage file was quoted only to the calendar distribution of the weekdays not considering the public holidays, while the 1975 and 1993-files slightly oversample the Sundays and public holidays. However, these differences underline the importance of applying a calibration (Figure 6).

To summarize the results before calibration: There are partially remarkable differences between old weights' totals and desired actual totals. The bias in the demographic representation in all American Heritage Time Use Data for market and non-market time use studies is considerable.

Misleading results have to be expected when the old survey weights are considered in particular according to

- the family context

- children in household

- family type

- the person's age structure (in particular the young and old)

- the day of the week distribution (public holidays)

as demographic variables, which indeed seems to be important for further substantive time use analyses. 


\section{Figure 6}

Representation of American Heritage Time Use Files 1965 - 1998/99 - Over- and underrepresentation compared to desired totals in \%: Representation of days of the week

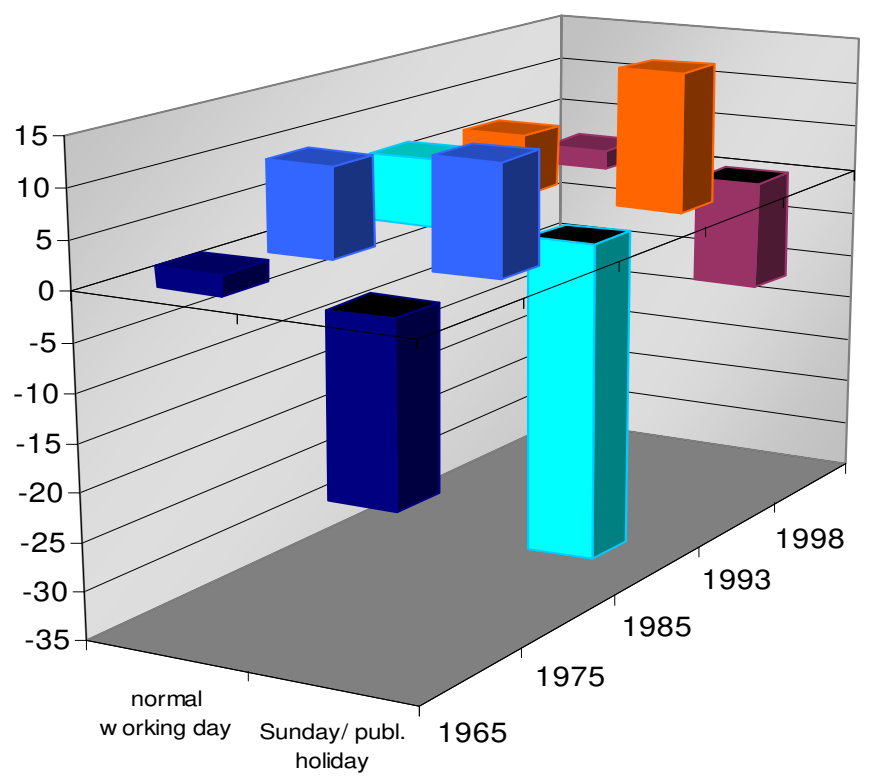

Source: American Heritage Time Use Files 1965 - 1998/99, own computation.

\section{New harmonised calibration: Calibration weights results and experiences}

The adjustment algorithm used in ADJUST converged after 14-17 iterations providing the desired new simultaneous weight for each single microunit in each AHTUD file. Thus, all the discussed differences between the respective actual total and the aggregated sociodemographic characteristic given the new weights indeed vanished (single log-files are available within Merz and Stolze, 2006).

The resulting new weights are available on request as ASCII-Files, connecting the identification variables of the different AHTUD files with the new weighting factor, and can be easily merged for standard statistic software or database applications ${ }^{16}$.

The new weights for the AHTUD files will now simultaneously fulfill the given aggregates of the respective CPS-data and population estimates. The frequency distributions of the old and new weights for all five heritage files are provided in Figure 7. Not discussing single results, however, one striking result is the enhanced variance of the new weights in all AHTUD files providing more reliable information with regard to more disaggregated analyses.

Experiences: The advantages as well as the difficulties of a calibration are obvious. It is highly important to balance between the depth of the aggregates, on one hand, and the variance of the weights, on the other hand.

16 CSV-File; Identifier followed by new weight, separated with semicolons. 
Figure 7

Frequency distributions of the old and new harmonised weights of the 1965 American Heritage Time Use Data (AHTUD) 1965 - 1998/99

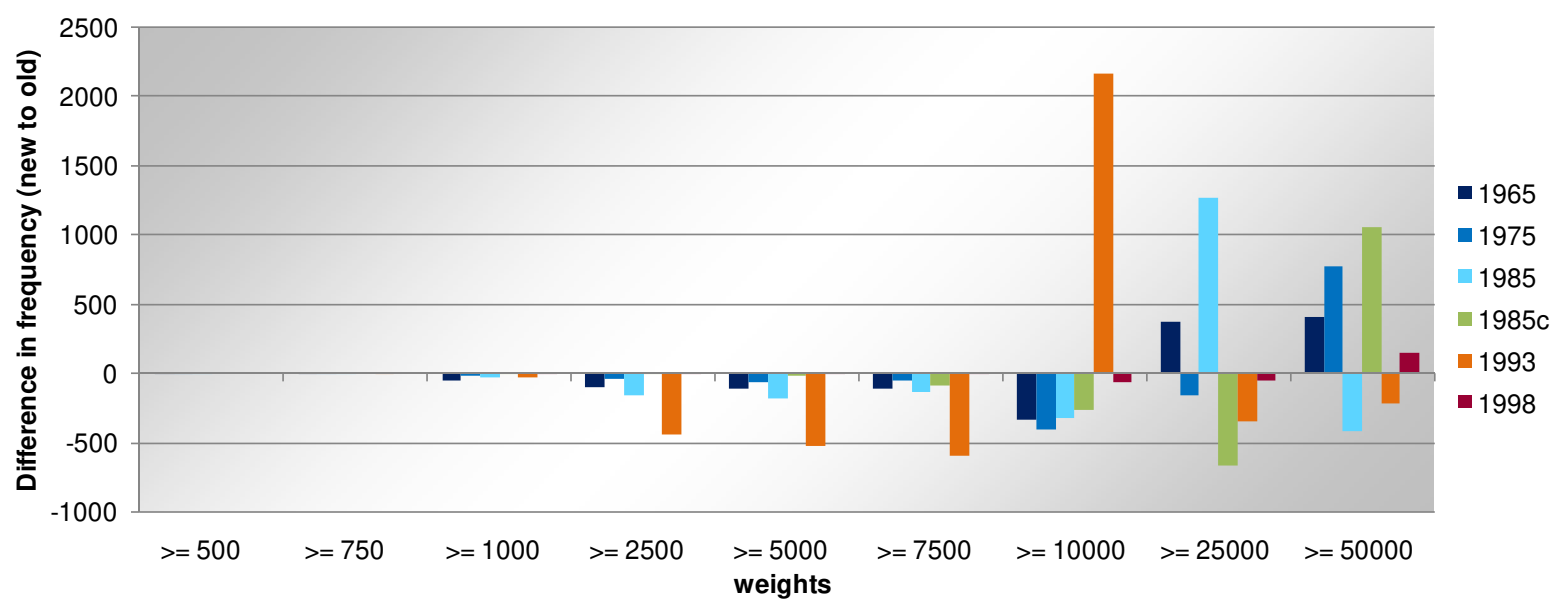

Source: American Heritage Time Use Files 1965 - 1998/99, own computation.

Though the algorithm was able to find a simultaneous solution after a few iterations, the sample size was too small to consider additional aggregates. Even in this constellation with relatively few restrictions to be achieved, there are some cases which must represent far more than a million citizens. Dealing with five samples simultaneously, the set of possible restrictions diminishes if all calibrations follow the same structure. Several calibration settings had to be tried before the selection of a suitable overall restriction set was possible. An additional effort was necessary to prepare the sample with the identification of adequate sample and available aggregate characteristics.

Finally, finding appropriate data for all these studies, reaching 40 years back in time, turned out to be a difficult and demanding task, since methods and surveys have changed quite a lot over this long period of time. Nevertheless, to save the in-depth information of the daily living situation of Americans over the past it was worth doing.

\section{Disentangling demographic from behavioural changes - recalibration of the US Heritage Files 1975-1999}

To illustrate the wide range of using calibration for time use analyses, we disentangled demographic from behavioural changes in the time use behaviour of the American Heritage Time Use Data by re-calibrating the AHTUD 1975 to 1999 files based on the demographic structure of 1965. These alternative sample weights use the demographic totals from the oldest survey in 1965 as the new demographic totals for the younger files within the new calibrations. 
With ADJUST the calibration converged rapidly after maximal 16 iterations providing the desired new weight for each microunit. The resulting weights are available as ASCII-Files on request. With the identification variables of the different AHTUD files and the new weighting factors, the results can easily be merged by standard statistic software or database applications. ${ }^{17}$ Needless to say, the new weights for the four younger AHTUDe files will now simultaneously fulfill the given aggregates of the respective 1965 CPS-data and population aggregates.

Table 4 summarises the relative differences in the population structure of the younger $\mathrm{AH}-$ TUD files compared to the 1965 totals before the re-calibration. The resulting structural differences are remarkable. Keeping in mind that every survey's sampling is different with quite remarkable biased survey weightings (see the above results), wide spread differences could be expected.

Further substantive results in disentangling demographic and time use behavioural changes with the US historic time use files with the above strategy of a re-calibration using a former population structure compared to other strategies are provided in St. Croix and Harvey (2005).

Table 4

Disentangling demographic from behavioural changes: Differences to the 1965 aggregates before re-calibration

\begin{tabular}{|c|c|c|c|c|c|c|c|c|}
\hline \multirow[t]{2}{*}{ Category } & \multirow{2}{*}{$\begin{array}{c}\text { Restr. } \\
\text { No. }\end{array}$} & \multirow{2}{*}{ Description } & \multicolumn{6}{|c|}{ Relative differences to aggregates $1965[\%]$} \\
\hline & & & 1965 & 1975 & 1985 & $1985 \mathrm{c}$ & 1993 & 1998 \\
\hline \multirow[t]{12}{*}{ Male \# age } & 1 & male, age $18-19$ & 3804236 & -54.6 & $-18,7$ & $-30,9$ & -74.2 & $-43,4$ \\
\hline & 2 & male, age $20-24$ & 6899289 & 10.7 & 43,2 & 24,2 & -63.1 & 11,8 \\
\hline & 3 & male, age $25-30$ & 5612436 & 40.3 & 65,2 & 75 & -29.6 & 101,3 \\
\hline & 4 & male, age $31-34$ & 5517566 & 22.0 & 70,5 & 66,7 & -19.4 & 84,3 \\
\hline & 5 & male, age $35-39$ & 5898942 & 19.0 & 36,6 & 55,9 & -8.7 & 67,5 \\
\hline & 6 & male, age $40-44$ & 6058104 & 4.5 & 7,8 & 1,2 & 0.4 & 60,7 \\
\hline & 7 & male, age $45-49$ & 5552528 & -16.4 & $-17,3$ & -2 & 70.6 & 84,4 \\
\hline & 8 & male, age $50-54$ & 5101484 & -1.2 & 4,5 & 5,5 & 78.9 & 46,5 \\
\hline & 9 & male, age 55-59 & 4582681 & 16.3 & 4,1 & 5,1 & 112.4 & 22,2 \\
\hline & 10 & male, age $60-64$ & 3583081 & -2.9 & 53,5 & 27,5 & 201.8 & 35 \\
\hline & 11 & male, age 65-69 & 2972192 & 66.3 & 39 & 32,6 & 219.4 & 88,8 \\
\hline & 12 & male, age 70+ & 5041923 & -23.3 & 87,8 & 120,9 & 120.4 & 25,1 \\
\hline \multirow[t]{2}{*}{ Female \# age } & 13 & female, age 18-19 & 3672040 & 0.5 & -3 & 0,5 & -67.9 & 38,3 \\
\hline & 14 & female, age 20-24 & 6847150 & 19.4 & 44,1 & 35,2 & -33.9 & 10,1 \\
\hline
\end{tabular}

17 CSV-File; Identifier followed by new weight, separated with semicolons. 
Table 4 (cont.)

Disentangling demographic from behavioural changes: Differences to the 1965 aggregates before re-calibration

\begin{tabular}{|c|c|c|c|c|c|c|c|c|}
\hline \multirow[t]{12}{*}{ Category } & \multirow{2}{*}{$\begin{array}{c}\text { Restr. } \\
\text { No. }\end{array}$} & \multirow{2}{*}{ Description } & \multicolumn{6}{|c|}{ Relative differences to aggregates 1965 [\%] } \\
\hline & & & 1965 & 1975 & 1985 & $1985 \mathrm{c}$ & 1993 & 1998 \\
\hline & 15 & female, age $25-30$ & 5727774 & 57.7 & 76,4 & 90,1 & -11.9 & 57,8 \\
\hline & 16 & female, age $31-34$ & 5607221 & 40.8 & 106,2 & 87,5 & -5.5 & 99,1 \\
\hline & 17 & female, age $35-39$ & 6121742 & 11.6 & 71,6 & 67,6 & -4.3 & 82,6 \\
\hline & 18 & female, age $40-44$ & 6368258 & -14.6 & 1,6 & 15 & 32.0 & 106,2 \\
\hline & 19 & female, age $45-49$ & 5827607 & -4.9 & 17,1 & 21,3 & 65.4 & 52,9 \\
\hline & 20 & female, age 50-54 & 5357560 & 1.5 & 3,1 & 12,1 & 115.6 & 22,2 \\
\hline & 21 & female, age 55-59 & 4922336 & -2.3 & 56,7 & 25,8 & 180.1 & 15 \\
\hline & 22 & female, age 60-64 & 3988792 & 36.1 & 36,9 & 33,3 & 230.1 & 33,8 \\
\hline & 23 & female, age $65-69$ & 3578099 & 26.7 & 36,4 & 17,2 & 207.6 & 6,8 \\
\hline & 24 & female, age $70+$ & 6859179 & -11.3 & 145,2 & 108,9 & 67.9 & 80,9 \\
\hline Children & 25 & children $<18$ in $\mathrm{HH}$ & $68,362,000^{*}$ & 133.3 & 68,4 & 55,7 & 116.9 & 156,5 \\
\hline \multirow[t]{2}{*}{ Marital status } & 26 & married & 84734000 & 34.0 & 29,5 & 30,9 & $\mathrm{n} / \mathrm{a}$ & 41,5 \\
\hline & 27 & single & 31945000 & -55.8 & 4,9 & 12,4 & $\mathrm{n} / \mathrm{a}$ & 17,2 \\
\hline \multirow[t]{2}{*}{$\begin{array}{l}\text { Occupational } \\
\text { status }\end{array}$} & 28 & full-time employed & $65,216,000^{*}$ & 19.8 & 67,9 & 42,3 & 67.0 & 82,2 \\
\hline & 29 & part-time employed & $11,148,000^{*}$ & -2.3 & 80,7 & 50,4 & 93.1 & 98,5 \\
\hline \multirow[t]{2}{*}{$\begin{array}{l}\text { Educational } \\
\text { attainment }\end{array}$} & 30 & none/ only elementary & 34045000 & -36.0 & $-40,8$ & $-66,6$ & -89.6 & $-72,9$ \\
\hline & 31 & some high school & 18617000 & -2.5 & $-1,4$ & $-26,4$ & -34.0 & $-5,9$ \\
\hline \multirow{3}{*}{$\begin{array}{l}\text { Educational } \\
\text { attainment }\end{array}$} & 32 & high school grad. & 31703000 & 36.3 & 84,6 & 95,6 & 100.1 & 78,8 \\
\hline & 33 & some college & 9139000 & 48.8 & 151,8 & 158,1 & 384.5 & 366,9 \\
\hline & 34 & college grad. or more & 9742000 & $\mathrm{n} / \mathrm{a}$ & 73,4 & 142,1 & 418.4 & $\mathrm{n} / \mathrm{a}$ \\
\hline \multirow[t]{2}{*}{ Weekday } & 35 & normal working day & 199 & 30.0 & 47,9 & 50,1 & 63.3 & 65,2 \\
\hline & 36 & $\begin{array}{l}\text { Sunday or } \\
\text { public holiday }\end{array}$ & 62 & 32.0 & 29,7 & -7 & 75.0 & 41,3 \\
\hline
\end{tabular}

Source: American Heritage Time Use Survey (AHTUD) files, own computations.

\section{$7 \quad$ Conclusions and recommendations}

As our analyses has shown, the former available calibration of the five American Heritage Time Use Data (AHTUD) files is seriously biased according to important demographic totals which in addition are of strategic importance for substantial time use analyses. It is important to emphasize that the enourmous wealth of indepth information of the American's daily liv- 
ing situation is unaffected by this calibration bias, since a proper re-calibration will solve this problem of demographic representativity. Our study reports a way to eliminate this bias and deliver a comprehensive harmonized demographic adjustment for all five incorporated U.S. heritage time use surveys.

Our calibration is theoretically founded on information theory, consistent with a simultaneous weighting, including hierarchical data like personal and family/household data. It ensures desired positive weights, considers substantial requirements for time use research analyses, and is harmonised in the demographic calibration characteristics for all heritage files. Our disentangling of demographic vs. time use behavioural changes by re-calibration illustrate the wide range of analysing possibilities using calibration in general.

The new harmonised calibration factors for all five AHTUD files are available on request. In addition, the alternative sample weights using the demographic totals from the oldest survey 1965 for all younger files to disentangle demographic vs. behavioural changes are available as well.

With the available new five sets of consistent and harmonised structured calibration factors, it is possible, in particular, to follow up American time use behaviour over the last 40 years now based on a reliable and valid demographic background delivering representative data for substantial time use analyses.

Based on our calibration experience we recommend above all that

- For any new time use survey, the calibration procedure and the single substantial definitions of the calibration characteristics with their totals must be documented carefully.

- A new calibration of new and actual American Time Use Surveys should be as close as possible to harmonised calibration characteristics when longitudinal analyses are to be done.

Since our software package ADJUST (http:ffb.uni-lueneburg.de/adjust) can be operated easily on every desktop-computer, any new simultaneous calibration can be carried out in a userfriendly and efficient manner. Also, sensitivity analyses with different totals resulting in different weighting sets will help further time use analyses to disentangle demographic effects from behavioural effects. 


\section{Appendix}

Table A1

Public holidays according to the U.S. code for the years of the AHTUD files

\begin{tabular}{|c|c|c|c|c|c|c|c|c|c|c|}
\hline \multirow{2}{*}{ Public Holiday } & \multicolumn{2}{|c|}{1965} & \multicolumn{2}{|c|}{1975} & \multicolumn{2}{|c|}{1985} & \multicolumn{2}{|c|}{1993} & \multicolumn{2}{|c|}{1998} \\
\hline & Date & Day & Date & Day & Date & Day & Date & Day & Date & Day \\
\hline New Year & $01 / 01$ & Fri & $01 / 01$ & Wed & $01 / 01$ & Tue & $01 / 01$ & Fri & $01 / 01$ & Thu \\
\hline Martin Luther King Day & $01 / 18$ & Mon & $01 / 20$ & Mon & $01 / 21$ & Mon & $01 / 18$ & Mon & $01 / 19$ & Mon \\
\hline Presidents' Day & $02 / 15$ & Mon & $02 / 17$ & Mon & $02 / 18$ & Mon & $02 / 15$ & Mon & $02 / 16$ & Mon \\
\hline Memorial Day & $05 / 31$ & Mon & $05 / 26$ & Mon & $05 / 27$ & Mon & $05 / 31$ & Mon & $05 / 25$ & Mon \\
\hline Independence Day & $\begin{array}{c}07 / 04^{*} \\
07 / 05\end{array}$ & $\begin{array}{l}\text { Sun } \\
\text { Mon }\end{array}$ & $07 / 04$ & Fri & 07/04 & Thu & $\begin{array}{c}07 / 04 * \\
07 / 05\end{array}$ & $\begin{array}{l}\text { Sun } \\
\text { Mon }\end{array}$ & $\begin{array}{c}07 / 04^{*} \\
07 / 03\end{array}$ & $\begin{array}{l}\text { Sat } \\
\text { Fri }\end{array}$ \\
\hline Labour Day & 09/06 & Mon & 09/01 & Mon & $09 / 02$ & Mon & 09/06 & Mon & $09 / 07$ & Mon \\
\hline Columbus Day & $10 / 11$ & Mon & $10 / 13$ & Mon & $10 / 14$ & Mon & $10 / 11$ & Mon & $10 / 12$ & Mon \\
\hline Veterans' Day & $11 / 11$ & Thu & $11 / 11$ & Tue & $11 / 11$ & Mon & $11 / 11$ & Thu & $11 / 11$ & Wed \\
\hline Thanksgiving & $11 / 25$ & Thu & $11 / 27$ & Thu & $11 / 28$ & Thu & $11 / 25$ & Thu & $11 / 26$ & Thu \\
\hline Christmas Day & $\begin{array}{c}12 / 25^{*} \\
12 / 24\end{array}$ & $\begin{array}{l}\text { Sat } \\
\text { Fri }\end{array}$ & $12 / 25$ & Thu & $12 / 25$ & Wed & $\begin{array}{c}12 / 25^{*} \\
12 / 24\end{array}$ & $\begin{array}{l}\text { Sat } \\
\text { Fri }\end{array}$ & $12 / 25$ & Fri \\
\hline
\end{tabular}

* If the public holiday occurs on a regular non-workday, the day immediately before or after that day will be public holiday instead. Source: US Code Title 5, part II, Subpart E, Chapter 61, Subchapter I, §6103; own arrangement. 
Table A2

Calibration variables of the AHTUD files used to build the calibration microdata-matrix (S)

\begin{tabular}{|c|c|c|c|c|c|c|c|c|c|c|c|c|}
\hline \multirow[b]{2}{*}{ Category } & \multirow{2}{*}{$\begin{array}{l}\text { Restriction } \\
\text { number }\end{array}$} & \multirow[b]{2}{*}{ Description } & \multicolumn{2}{|c|}{1965} & \multicolumn{2}{|c|}{1975} & \multicolumn{2}{|c|}{1985} & \multicolumn{2}{|c|}{ 1992-94 } & \multicolumn{2}{|c|}{ 1998-99 } \\
\hline & & & Variable & Value & Variable & Value & Variable & Value & Variable & Value & Variable & Value \\
\hline \multirow[t]{12}{*}{ Male \# age } & 01 & male, age $18-19$ & $\operatorname{sex}$ & 1 & v403 & 1 & sex & 1 & sex & 1 & rsex & 1 \\
\hline & 02 & male, age $20-24$ & $\begin{array}{c}\# \\
\text { age }\end{array}$ & 1 & $\begin{array}{c}\# \\
\mathrm{v} 414\end{array}$ & 1 & $\begin{array}{c}\# \\
\text { age }\end{array}$ & 1 & $\begin{array}{c}\# \\
\text { age }\end{array}$ & 1 & $\begin{array}{c}\# \\
\text { rage }\end{array}$ & 1 \\
\hline & 03 & male, age $25-30$ & & 1 & & 1 & & 1 & & 1 & $\begin{array}{l}\text { (computed } \\
\text { from }\end{array}$ & 1 \\
\hline & 04 & male, age $31-34$ & & 1 & & 1 & & 1 & & 1 & $\begin{array}{l}\text { birthyear } \\
\text { in variable }\end{array}$ & 1 \\
\hline & 05 & male, age $35-39$ & & 1 & & 1 & & 1 & & 1 & 'p3a') & 1 \\
\hline & 06 & male, age $40-44$ & & 1 & & 1 & & 1 & & 1 & & 1 \\
\hline & 07 & male, age $45-49$ & & 1 & & 1 & & 1 & & 1 & & 1 \\
\hline & 08 & male, age 50-54 & & 1 & & 1 & & 1 & & 1 & & 1 \\
\hline & 09 & male, age $55-59$ & & 1 & & 1 & & 1 & & 1 & & 1 \\
\hline & 10 & male, age $60-64$ & & 1 & & 1 & & 1 & & 1 & & 1 \\
\hline & 11 & male, age $65-69$ & & 1 & & 1 & & 1 & & 1 & & 1 \\
\hline & 12 & male, age $70+$ & & 1 & & 1 & & 1 & & 1 & & 1 \\
\hline \multirow[t]{5}{*}{ Female \# age } & 13 & female, age 18-19 & & 2 & & 2 & & 2 & & 2 & & 2 \\
\hline & 14 & female, age $20-24$ & & 2 & & 2 & & 2 & & 2 & & 2 \\
\hline & 15 & female, age $25-30$ & & 2 & & 2 & & 2 & & 2 & & 2 \\
\hline & 16 & female, age $31-34$ & & 2 & & 2 & & 2 & & 2 & & 2 \\
\hline & 17 & female, age $35-39$ & & 2 & & 2 & & 2 & & 2 & & 2 \\
\hline
\end{tabular}


Joachim Merz and Henning Stolze: Representative time use data and new harmonised calibration of the American Heritage Time Use Data (AHTUD) 1965 - 1999

Table A2 (cont.)

Calibration variables of the AHTUD files used to build the calibration microdata-matrix (S)

\begin{tabular}{|c|c|c|c|c|c|c|c|c|c|c|c|c|}
\hline \multirow[b]{2}{*}{ Category } & \multirow{2}{*}{$\begin{array}{c}\text { Restriction } \\
\text { number }\end{array}$} & \multirow[b]{2}{*}{ Description } & \multicolumn{2}{|c|}{1965} & \multicolumn{2}{|c|}{1975} & \multicolumn{2}{|c|}{1985} & \multicolumn{2}{|c|}{ 1992-94 } & \multicolumn{2}{|c|}{ 1998-99 } \\
\hline & & & Variable & Value & Variable & Value & Variable & Value & Variable & Value & Variable & Value \\
\hline \multirow[t]{7}{*}{ Female \# age } & 18 & female, age $40-44$ & & 2 & & 2 & & 2 & & 2 & & 2 \\
\hline & 19 & female, age $45-49$ & & 2 & & 2 & & 2 & & 2 & & 2 \\
\hline & 20 & female, age 50-54 & & 2 & & 2 & & 2 & & 2 & & 2 \\
\hline & 21 & female, age 55-59 & & 2 & & 2 & & 2 & & 2 & & 2 \\
\hline & 22 & female, age $60-64$ & & 2 & & 2 & & 2 & & 2 & & 2 \\
\hline & 23 & female, age $65-69$ & & 2 & & 2 & & 2 & & 2 & & 2 \\
\hline & 24 & female, age $70+$ & & 2 & & 2 & & 2 & & 2 & & 2 \\
\hline Children & 25 & children $<18$ years in $\mathrm{HH}$ & under 18 & & v415 & & $\begin{array}{c}\text { under } \\
18\end{array}$ & & kid\# & & $\mathrm{p} 2$ & \\
\hline \multirow{3}{*}{$\begin{array}{l}\text { Marital } \\
\text { status }\end{array}$} & 26 & married & marital & 1 & v32 & 1 & marital & 1 & $\mathrm{n} / \mathrm{a}$ & -- & p6 & 1 \\
\hline & 27 & single (never married) & & 4 & & 5 & & 4 & & -- & & 5 \\
\hline & 28 & divorced/ separated/ widowed & & $2 ; 3$ & & $2 ; 3 ; 4$ & & $2 ; 3$ & & -- & & $2 ; 3 ; 4$ \\
\hline \multirow[t]{2}{*}{ Occupational } & 29 & full-time employed & full & 1 & v125 & $>=30$ & full & 1 & employ & 1 & p7 & 1 \\
\hline & 30 & part-time employed & part & 1 & & $<30$ & part & 1 & & 2 & & 2 \\
\hline
\end{tabular}


Table A2 (cont.)

Calibration variables of the AHTUD files used to build the calibration microdata-matrix (S)

\begin{tabular}{|c|c|c|c|c|c|c|c|c|c|c|c|c|}
\hline \multirow[b]{2}{*}{ Category } & \multirow{2}{*}{$\begin{array}{c}\text { Restriction } \\
\text { number }\end{array}$} & \multirow[b]{2}{*}{ Description } & \multicolumn{2}{|c|}{1965} & \multicolumn{2}{|c|}{1975} & \multicolumn{2}{|c|}{1985} & \multicolumn{2}{|c|}{$1992-94$} & \multicolumn{2}{|c|}{ 1998-99 } \\
\hline & & & Variable & Value & Variable & Value & Variable & Value & Variable & Value & Variable & Value \\
\hline \multirow{5}{*}{$\begin{array}{l}\text { Educational } \\
\text { attainment }\end{array}$} & 31 & none/ only elementary & educ & $0 ; 1$ & v118 & $0-8$ & educ & $0 ; 1$ & educ & $0-8$ & p5 & $0-8$ \\
\hline & 32 & some high school & & 2 & & $9-11$ & & 2 & & $9-11$ & & $9-11$ \\
\hline & 33 & high school grad. & & 3 & & 12 & & 3 & & 12 & & 12 \\
\hline & 34 & some college & & 4 & & $13-15$ & & 4 & & $13-15$ & & $13-15$ \\
\hline & 35 & college grad. or more & & 5 & & $>=16$ & & 5 & & $>=16$ & & $>=16$ \\
\hline \multirow[t]{2}{*}{ Weekday } & 36 & normal working day & day & $1-4$ & $\begin{array}{c}\text { v432 } \\
\text { (only } \\
\text { for } \\
\text { wave 1) }\end{array}$ & $1-4$ & day & $1-4$ & day & $1-4$ & pday & $1-4$ \\
\hline & 37 & Sunday or public holiday & & 7 & & 7 & & 7 & & 7 & & 7 \\
\hline ID & & respondents' ID & \multicolumn{2}{|c|}{ id } & \multicolumn{2}{|c|}{ Id } & \multicolumn{2}{|c|}{ respid } & \multicolumn{2}{|c|}{ respid } & \multicolumn{2}{|c|}{ respid } \\
\hline Weight & & available weights & \multicolumn{2}{|c|}{ demowgt } & \multicolumn{2}{|c|}{ v7973 } & \multicolumn{2}{|c|}{ wt } & \multicolumn{2}{|c|}{ adwta } & \multicolumn{2}{|c|}{ wt } \\
\hline
\end{tabular}

Source: AHTUD files, own arrangement. 
Joachim Merz and Henning Stolze: Representative time use data and new harmonised calibration of the American Heritage Time Use Data (AHTUD) 1965 - 1999

\section{References}

ADJUST for Windows - A software package to achieve representative microdata by the minimum information loss principle, http://ffb.uni-lueneburg.de/adjust.

Becker, G.S. (1965), A theory of the allocation of time, in: Economic Journal, Vol. 75, 493-517.

Bishop, Y.M. and S.E. Fienberg (1975), Discrete multivariate analysis: Theory and practice, Mass.: MIT-Press, Cambridge.

Bridges, B. jr. and M.P. Johnston (1976), Estimation of social security taxes on the March current population survey, Studies of Income Distribution, No. 4 (Social Security Administration, Office of Research and Statistics, US Department of Health, Education and Welfare, Washington, D.C.

Bureau of Labour Statistics (1988), Labour force statistics derived from the Current Population Survey, 1948-87, Bulletin 2307.

Byron, R.P. (1978), The estimation of large social account matrices, in: Journal of the Royal Statistical Society, Series A, 141, Part 3, 359-367.

CBS (Centraal Bureau voor de Statistiek) (1999), Living conditions of dutch population: Part 3, Time allocation and social participation, Voorburg/Heerlen, Netherlands.

Chiappori, P.-A. (1988), Rational household labour supply, in: Econometrica, Vol. 56, 63-89.

Chiappori, P.-A., Blundell, R., Magnac, T. and C. Meghir (2007), Collective labour supply: Heterogeneity and nonparticipation, in: Review of Economic Studies, Vol. 74, 417-447.

Citro C.F. and E.A. Hanushek (eds.) (1991a), Improving information for social policy decisions, The uses of microsimulation modeling: Review and recommendations, Vol. I, National Research Council, Washington.

Citro C.F. and E.A. Hanushek (eds.) (1991b), Improving information for social policy decisions, The uses of microsimulation modeling: Technical papers, Vol. II, National Research Council, Washington.

Deming, W.E. and F.F. Stephan (1940), On a least square adjustment of a sampled frequency table when the expected marginal totals are known, in: The Annals of Mathematical Statistics, Vol. 11, 427-444.

Deville, J.-C. and C.-E. Särndal (1992), Calibration estimators in survey sampling, in: Journal of the American Statistical Association, Vol. 87, No. 418, 375-382.

Estevao, V.M. and C.-E. Särndal (2006), Survey estimates by calibration on complex auxiliary information, in: International Statistical Review, Vol. 74, No. 2, 127-147.

Finke, R. and H. Theil (1984), An extended version of minimum information estimation of allocation models, in: Economics Letters, Vol. 15, 229-233.

Flood, L. (1988), Effects of taxes on mon-market work: The swedish case, in: Journal of Public Economics, Vol. 36, 259-267.

Frank, M. and P. Wolfe (1956), An algorithm for quadratic programming, in: Naval Research Logistics Quarterly, Vol. 3, 95-100.

Galler, H.P. (1977), Die Ermittlung eines konsistenten Hochrechnungsrahmens für das IMDAF-69, SPESArbeitspapier Nr. 77, Frankfurt/Mannheim.

Galler, H.P. and G. Wagner (1986), The microsimulation model of the Sfb 3 for the analysis of economic and social policies, in: Orcutt, G.H., Merz, J. and H. Quinke (eds.), Microanalytic simulation models to support social and financial policy, North Holland, Amsterdam, 227-247.

Harding, A. (ed.) (1996), Microsimulation and public policy, North Holland, Amsterdam.

Harvey, A. and A. St. Croix (2005), Report on data assembly and preliminary evaluation, Yale program of nonmarket accounts: Dataset assessments, Halifax, Canada.

Harvey, A., Elliott, D. and D. Procos (1977), Sub-populations relevant to the study of the use of time: A working paper, Halifax, Canada.

Hildreth, C. (1957), A quadratic programming procedure, in: Naval Research Logistics Quarterly, Vol. 14, 7985.

Houthakker, H.S. (1960), The capacity method of quadratic programming, in: Econometrica, Vol. 28, 62-87. 
Joachim Merz and Henning Stolze: Representative time use data and new harmonised calibration of the American Heritage Time Use Data (AHTUD) 1965 - 1999

Ironmonger, D.S. (1972), New commodities and consumer behaviour, Cambridge University Press, Cambridge. Jaynes, E.T. (1957), Information theory and statistical mechanics I, in: Physics Review, Vol. 106, 620-630.

Juster, T.F., Hill, M.S., Stafford, F.P. and J. Eccles Parsons (1983), 1975-1981 Time Use Longitudinal Panel Study, Survey Research Center, Institute for Social Research, University of Michigan, Ann Arbor, Michigan.

Killingsworth, M. (1983), Labour supply, Cambridge University Press, Cambridge.

Killingsworth, M.R. and J.J. Heckmann (1986), Female labour supply: A survey, in: Ashenfelter, O. and Layard, R. (eds.), Handbook of Labour Economics, Vol. I, Amsterdam/New York, 103-204.

Lancaster, K. (1966), A new approach to consumer theory, in: Journal of Political Economy, Vol. 73, 132-157.

Le Guennec, J. and O. Sautory (2003), La macro Calmar2, manuel d'utilisation, Document interne INSEE.

Legal Information Institute (2005), U.S. Code Collection, Cornell.

Merz, J. (1980), Prognosegüte und Spektraleigenschaften ökonomischer Modelle, in: Stöppler, S. (ed.), Dynamische ökonomische Systeme - Analyse und Steuerung, 2nd edition, Gabler, Wiesbaden, 31-66.

Merz, J. (1983a), Die konsistente Hochrechnung von Mikrodaten nach dem Prinzip des minimalen Informationsverlustes, in: Allgemeines Statistisches Archiv, Vol. 67, No. 4, 342-366.

Merz, J. (1983b), The adjustment of microdata using the Kalman filtering procedure and optimal control theory, Sfb 3-Working Paper No. 122, Frankfurt/Mannheim.

Merz, J. (1985), Ein modifiziertes Newton-Verfahren zur Lösung des Hochrechnungsproblems nach dem Prinzip des minimalen Informationsverlustes, in: Computing, Vol. 35, 51-61.

Merz, J. (1986), Structural adjustment in static and dynamic microsimulation models, in: Orcutt, G., Merz, J. and H. Quinke (eds.), Microanalytic simulation models to support social and financial policy, North Holland, Amsterdam, 423-446.

Merz, J. (1989), Markt- und nichtmarktmäßige Aktivitäten privater Haushalte - Theoretischer Ansatz, repräsentative Mikrodaten, mikroökonometrische Analyse und Mikrosimulation wirtschafts- und sozialpolitischer Maßnahmen für die Bundesrepublik Deutschland, Habilitation, Frankfurt.

Merz, J. (1990), The 1990 German tax reform - Microsimulation of time allocation effects in the formal and informal economy, in: Brunner, J.K. and H.G. Petersen (eds.), Simulation models in tax and transfer policy, Campus, Frankfurt/M., New York.

Merz, J. (1991a), Microsimulation - A survey of principles, developments and applications, in: International Journal of Forecasting, Vol. 7, 77-104.

Merz, J. (1991b), Wirkungen der Steuerreform 1990 auf Nebenerwerb und Schwarzarbeit, in: Döring, D. and P.B. Spahn (eds.), Steuerreform als gesellschaftliche Aufgabe der neunziger Jahre, Duncker und Humblot, Berlin, 283-303.

Merz, J. (1994), Microdata adjustment by the minimum information loss principle, FFB-Discussion paper No. 10, Forschungsinstitut Freie Berufe, Fachbereich Wirtschafts- und Sozialwissenschaften, Universität Lüneburg, Lüneburg.

Merz, J. (1996a), Market and non-market labour supply and the impact of the recent German tax reform - Incorporating behavioural response, in: Ann Harding (ed.), Microsimulation and public policy, (IARIW Special conference on microsimulation and public policy, Canberra, Australia, 5.-9.12.1993), North Holland, Amsterdam, 177-202.

Merz, J. and H. Stolze (2006), Representative time use data and calibration of the American Time Use Studies 1965-1999, FFB-Discussion paper No. 54, Department of Economic, Behavioural and Law Sciences, Leuphana University of Lüneburg, Lüneburg.

Merz, J. and H. Stolze (2007), ADJUST for Windows - A software package to achieve representative microdata by the minimum information loss principle, http://ffb.uni-lueneburg.de/adjust.

Merz, J. and K.G. Wolff (1993), The shadow economy: Illicit work and household production - A microanalysis of West Germany, in: The Review of Income and Wealth, Vol. 39, 177-194.

Mitton, L., Sutherland, H. and M. Weeks (eds.) (2000), Microsimulation modelling for policy analysis, Cambridge University Press, Cambridge.

Mosteller, F. (1968), Association and estimation in contingency tables, in: Journal of the American Statistical Association, Vol. 63, 1-28.

Muth, R.F. (1966), Household production and consumer demand functions, in: Econometrica, Vol. 34, 699-708.

Nieuwenbroek, N. and H.J. Boonstra (2002), Bascula 4.0 reference manual, Statistics Netherlands. 
Joachim Merz and Henning Stolze: Representative time use data and new harmonised calibration of the American Heritage Time Use Data (AHTUD) 1965 - 1999

Oh, H.L. and F. Scheuren (1980), Multivariate raking ratio estimation in the 1973 exact match study, Studies from Interagency Data Linkages Report No. 11, U.S. Department of Health, Education and Welfare, Washington, D.C.

Orcutt, G., Merz, J. and H. Quinke (eds.) (1986), Microanalytic simulation models to support social and financial policy, North Holland, Amsterdam.

Robinson, J.P. (1977), How Americans used time in 1965, Institute for Social Research, University of Michigan, Ann Arbor, Michigan.

Robinson, J.P. (1985), Americans' use of time, Survey Research Center, College Park, MD: University of Maryland.

Robinson, J.P., Bianchi, S.M.and S. Presser (1999), Family interaction, social capital, and trends in time use, 1998-1999, Survey Research Center, College Park, MD: University of Maryland.

Särndal, C.-E. and S. Lundström (2005), Estimation in surveys with nonresponse, John Wiley \& Sons, Chichester (UK).

Shore, J.E. and R.W. Johnson (1980), Axiomatic derivation of the principle of maximum entropy and the principle of minimum cross-entropy, in: IEEE Trancsactions on Information Theory, Vol. IT-26, 28-37.

St.Croix, A. and A.S. Harvey (2005), Report on data assembly and preliminary evaluation, Yale Program of Non-market Accounts: Dataset Assessments, Time Use Research Program (TURP), Saint Mary's University, Halifax, Canada.

Statistisches Bundesamt (1960), Stichproben in der amtlichen Statistik, Stuttgart/Mainz.

Stone, R. (1976), The development of economic data systems, in: Pyatt, G. et al. (eds.), Social accounting for development planning with special reference to Sri Lanka, Cambridge University Press, Cambridge.

The American Heritage Time Use Study (AHTUS), www.timeuse.org/ahtus/.

Theil, H. (1967), Economics and information theory, North Holland, Amsterdam.

Theil, H. (1972), Statistical decomposition analysis, North Holland, Amsterdam.

Theil, H., Finke, R. and L.R. Flood (1984), Minimum information estimation of allocation models, in: Economics Letters, Vol. 15, 251-256.

Triplett, T. (1995), Data collection methods report for estimating exposure to pollutants through human activity pattern data, A national micro-behavioural approach, Survey Research Center, College Park, MD: University of Maryland.

U.S. Census Bureau (2004), Annual social and economic supplement: 2003 Current Population Survey, Current Population Reports, Series P20-553, "America's Families and Living Arrangements: 2003" and earlier reports, retrieved February 2005, from http://www.census.gov/population/socdemo/hh-fam/tabCH1.pdf.

U.S. Census Bureau (n.d.), retrieved February 2005, from http://www.census.gov/popest/archives/1990s.

U.S. Census Bureau (n.d.), National estimates, retrieved February 2005, from http://www.census.gov/ popest/archives/pre-1980/PE-11.html.

U.S. Census Bureau, (n.d.), Quarterly population estimates, retrieved February 2005, from http://www.census.gov/popest/archives/1980s/80s_nat_detail.html.

U.S. Census Bureau. (2005), Table A-1. Years of school completed by people 25 years and over, by age and sex: Selected years 1940 to 2004, retrieved February 2005, from http://www.census.gov/ population/socdemo/education/tabA-1.pdf.

Vanderhoeft, C. (2003), g-Calib Release 2.0 - Supplement to the manual for release 1.0, Statistics Belgium.

Wauschkuhn, U. (1982), Anpassung von Stichproben und n-dimensionalen Tabellen an Randbedingungen, Oldenbourg, München/Wien. 